\title{
Equilibrium Constants of Some Reactions Involved in the Production of 1,3-Butadiene ${ }^{1}$
}

\author{
By Ferdinand G. Brickwedde, Morris Moskow, and John G. Aston²
}

\begin{abstract}
Thermodynamic functions including free energy, enthalpy, entropy, and specific heat, are given for the compounds butadiene, benzene, cyclonexane, ethane, ethylene, ethyl alcohol and water and for the elements carbon (graphite), hydrogen and oxygen. From these are calculated and tabulated values of equilibrium constants for reactions of interest in connection with the production of 1,3-butadiene for synthetic rubber. Comparisons are made between table values and available experimental data on equilibrium constants, gaseous specific heats and entropies. The cracking of hydrocarbons is discussed and the importance of reaction rates in determining the amounts of reaction products is noted.
\end{abstract}

\section{Introduction}

In an earlier publication the measured thermal properties of 1,3-butadiene including heat capacities down to $15^{\circ} \mathrm{K}$ were used to determine the entropy and enthalpy of butadiene to $300^{\circ} \mathrm{K}$ $[1,2]^{3}$ With these calorimetric data and the most recent spectroscopic data, the thermodynamic functions for butadiene were then extended to higher temperatures. These were combined with the thermodynamic functions for $n$-butane and the $n$-butenes to calculate the equilibrium constants for the dehydrogenation reactions of $n$ butane and $n$-butenes used in the manufacture of butadiene from petroleum and natural gas. [3, 4].

In the present paper are given values for thermodynamic functions and properties of a number of other compounds for use in calculations of equilibria occurring in other reactions involved in the commercial production of 1,3-butadiene for synthetic rubber. These compounds are benzene, cyclohexane, ethane, ethylene, ethyl alcohol, and water. Tables for the elements graphite, hydrogen, and oxygen also have been included. Tables

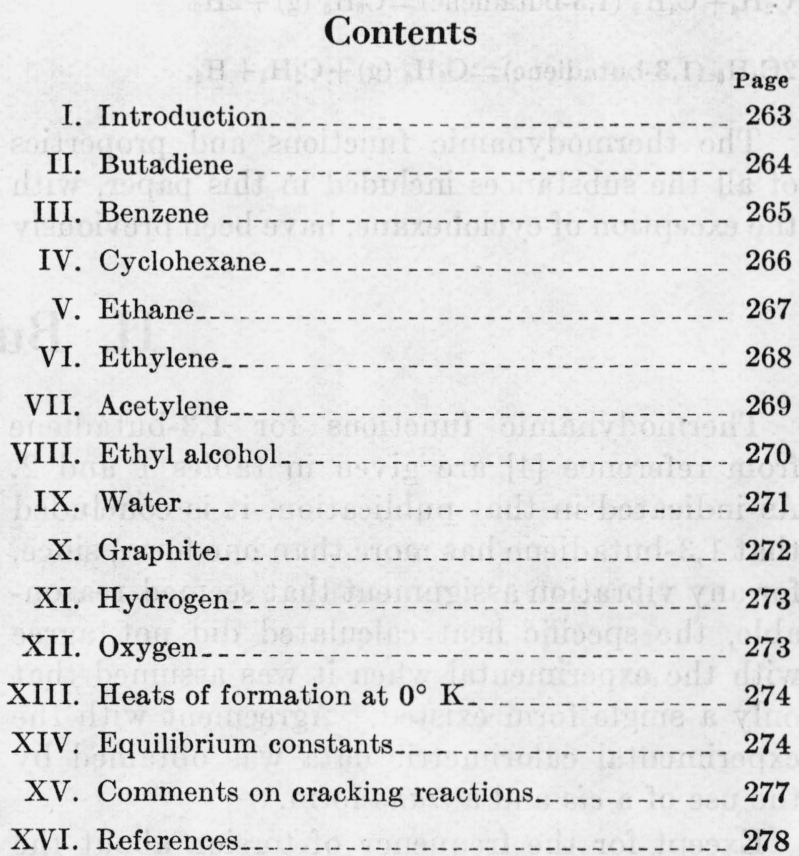

1 This paper is a revision of a report entitled, "Equilibrium constants of some reactions involved in the production of 1,3 -butadiene," submitted to the Office of the Rubber Director, March 24, 1944.

2 Director, Cryogenic Laboratory, Pennsylvania State College.

${ }^{3}$ Figures in brackets indicate literature references at the end of this paper. 
of equilibrium constants are given for the following reactions:

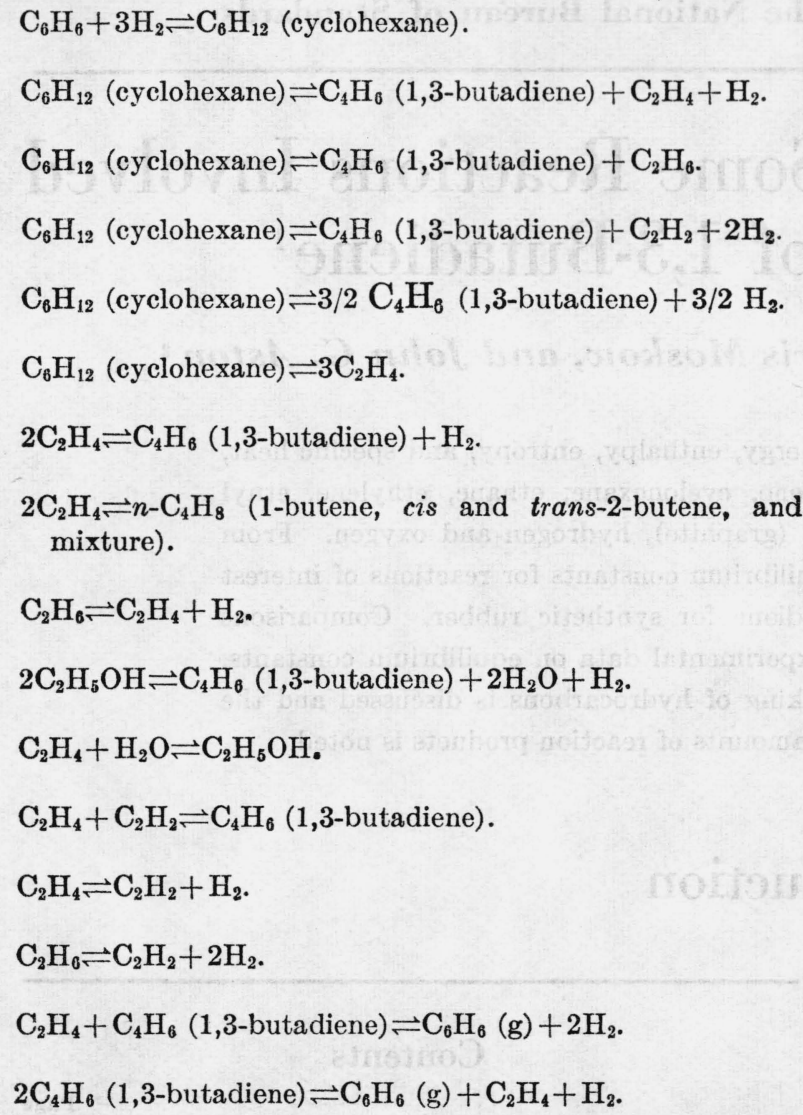

The thermodynamic functions and properties of all the substances included in this paper, with the exception of cyclohexane, have been previously calculated and published by others. However, new values for these functions and properties have been calculated for this paper, taking account of the latest spectroscopic and calorimetric data and by using the latest values of the fundamental physical constants. ${ }^{4}$ In a number of cases, the frequency assignments adopted cannot be regarded as certain but appear to be the most reasonable that have been proposed. It is thought that, in general, further improvements in the values taken for the fundamental frequencies given in this paper would result in only small changes of the calculated thermodynamic properties.

The thermodynamic functions and properties are given in tables 1 to $24 .^{5}$ Data and calculations upon which these tables are based are discussed in sections II to XI. Comparisons between calculated and experimental entropies and heat capacities are included for most of the compounds. The heats of formation of the compounds are discussed in section XII. The equilibrium constants of the reactions are given in tables 25 to 29 and are discussed in section XIII. In section XIV the results of some investigations on cracking reactions are compared with theoretically predicted equilibrium concentrations.

4 The physical constants include $h c / k=1.4384 \mathrm{~cm}$ deg, $R=1.98714$ artificial cal deg-1 mole ${ }^{-1}$ or $8.3144 \times 10^{7} \mathrm{erg} \mathrm{deg}^{-1} \mathrm{~mole}^{-1}$, and $N_{0}=6.0228 \times 10^{23} \mathrm{~mole}^{-1}$, with 1 artificial calorie defined as 4.1833 international joules. The atomic weights used are hydrogen 1.0080 , carbon 12.01 , and oxygen 16 .

3 In these tables the following conventions have been adopted: For enthalpy, $H^{\circ}$, and for free energy, $F^{\circ}$, the quantities are given as values above assumed zeros for the elements in their standard states at $0^{\circ} \mathrm{K} . \Delta H^{\circ}, \Delta F^{\circ}$, and $K$, respectively, are the enthalpy of formation, the free energy of formation, and the equilibrium constant of formation of the compound from the elements in their standard states at the temperature $T$.

\section{Butadiene}

Thermodynamic functions for 1,3-butadiene from reference [4] are given in tables 1 and 2 . As indicated in that publication, it is concluded that 1,3-butadiene has more than one form, since, for any vibration assignment that seemed reasonable, the specific heat calculated did not agree with the experimental when it was assumed that only a single form existed. Agreement with the experimental calorimetric data was obtained by the use of a cis and a trans form.

Except for the frequency of torsion about the central C-C bond, the distribution of energy levels has been assumed to be statistically the same for the cis as for the trans variety. The frequency assignment for the trans variety is mainly that of Bradacs and Kahovec [5]. It differs in the following. The observed Raman line $340 \mathrm{~cm}^{-1}$ that Bradacs and Kohovec assigned, with expressed doubt, to the fundamental of the middle $\mathrm{C}-\mathrm{C}$ torsional vibration was assigned by us to the first overtone of this vibration. For double-bond torsions the observed $520 \mathrm{~cm}^{-1}$ and a calculated $667 \mathrm{~cm}^{-1}$ based on ethylene have been used. For the skeletal deformation frequency $\omega_{5}$, the $520 \mathrm{~cm}^{-1}$ used by Bradacs and Kahovec has been replaced by $326 \mathrm{~cm}^{-1}$ on the basis of forceconstant calculations and the calorimetric data. The barrier heights are $5,000 \mathrm{cal} \mathrm{mole} \mathrm{e}^{-1}$ for the trans form and $2,575 \mathrm{cal} \mathrm{mole}^{-1}$ for the cis form. 
TABLE 1.-Heat capacity at constant pressure, heat content, and related quantities of 1,3-butadiene in the ideal gas state

$\left[E_{0}^{*}=30,200 \mathrm{cal} \mathrm{mole}^{-1}\right]$

\begin{tabular}{|c|c|c|c|c|}
\hline$T$ & $\frac{H^{\circ}-E_{0}^{0}}{T}$ & $H^{\circ}$ & $\Delta H^{\circ}$ & $C_{p}^{\circ}$ \\
\hline${ }^{\circ} \mathrm{K}$ & $\underset{\text { mole }^{-1}}{\text { cal deg-1 }}$ & cal mole-1 & cal mole-1 & $\begin{array}{c}\text { cal deg-1 } \\
\text { mole }\end{array}$ \\
\hline 298. 16 & 12.16 & 33,830 & 26,750 & 19.01 \\
\hline 300.00 & 12. 20 & 33,860 & 26,730 & 19.11 \\
\hline 400 & 14. 59 & 36,040 & 25,830 & 24. 29 \\
\hline 500 & 16.97 & 38,690 & 25,120 & 28.52 \\
\hline 600 & 19. 18 & 41,710 & 24,540 & 31.84 \\
\hline 700 & 21.19 & 45,040 & 24,080 & 34.55 \\
\hline 800 & 23.01 & 48,610 & 23,710 & 36.84 \\
\hline 900 & 24.66 & 52,390 & 23,420 & 38.81 \\
\hline 1,000 & 26.16 & 56,360 & 23,210 & 40.52 \\
\hline 1,100 & 27.54 & 60,490 & 23,060 & 42.02 \\
\hline 1,200 & 28.80 & 64,760 & 22,980 & 43. 32 \\
\hline 1,300 & 29.96 & 69,150 & 22,940 & 44.47 \\
\hline 1,400 & 31.03 & 73,650 & 22,950 & 45.47 \\
\hline 1,500 & 32.02 & 78,240 & 22,980 & 46.34 \\
\hline
\end{tabular}

$\Delta H^{\circ}$ is the enthalpy of formation of 1,3-butadiene from its elements in their standard states at the temperature $T$.
TABLE 2.-Entropy, free energy, and related quantities of 1,3-butadiene in the ideal gas state at 1-atmosphere pressure

$\left[E_{0}^{\circ}=30,200 \mathrm{cal} \mathrm{mole}^{-1}\right]$

\begin{tabular}{|c|c|c|c|c|c|}
\hline$T$ & $-\left(\frac{F^{\circ}-E_{0}^{\circ}}{T}\right)$ & $S^{\circ}$ & $-F^{\circ}$ & $\Delta F^{\circ}$ & ${ }^{a} \log _{10} K$ \\
\hline & cal deg-1 & cal dcg-1 & & & $-\Delta F^{\circ} / R T$ \\
\hline${ }^{\circ} \mathrm{K}$ & mole $e^{-1}$ & mole-1 & cal mole-1 & cal mole-1 & 2.3026 \\
\hline 298.16 & 54.46 & 66.62 & $-13,960$ & 36,430 & -26.707 \\
\hline 300.00 & 54.54 & 66.74 & $-13,840$ & 36,490 & -26.587 \\
\hline 400 & 58.38 & 72.97 & $-6,850$ & 39,890 & -21.793 \\
\hline 500 & 61.89 & 78.86 & +740 & 43,490 & -19.009 \\
\hline 600 & 65.18 & 84.36 & 8,920 & 47,210 & -17.198 \\
\hline 700 & 68.29 & 89.48 & 17,600 & 51,040 & -15.934 \\
\hline 800 & 71.24 & 94.25 & 26,790 & 54,920 & -15.003 \\
\hline 900 & 74.05 & 98.71 & 36,440 & 58,830 & -14.287 \\
\hline 1,000 & 76.72 & 102.88 & 46,520 & 62,780 & -13.721 \\
\hline 1,100 & 79.28 & 106.82 & 57,010 & 66,740 & -13.260 \\
\hline 1,200 & 81.73 & 110.53 & 67,880 & 70,720 & -12.880 \\
\hline 1,300 & 84.09 & 114.05 & 79,110 & 74,690 & -12.557 \\
\hline 1,400 & 86.35 & 117.38 & 90,680 & 78,670 & -12.281 \\
\hline 1,500 & 88.52 & 120.54 & 102,580 & 82,660 & -12.043 \\
\hline
\end{tabular}

- $\Delta F^{\circ}$ and $K$ are the free-energy change and equilibrium constant, re spectively, for the reaction forming 1, 3-butadiene from its elements in their standard states at $T^{\circ} \mathrm{K}$.

\section{Benzene}

The frequencies assigned to the fundamental modes of vibration of the benzene molecule by K. S. Pitzer and D. W. Scott were used for this paper [6]. These frequencies in centimeters ${ }^{-1}$ are as follows:

\section{Carbon skeleton frequencies:}

Vibrations in the plane of the molecule: $\omega_{1}=\omega_{2}=606, \quad \omega_{3}=1011, \quad \omega_{4}=992, \quad \omega_{5}=\omega_{6}=1485$, $\omega_{7}=\omega_{8}=1596$, and $\omega_{9}=(1693)$.

Vibrations out of the plane of the molecule: $\gamma_{1}=(685)$ and $\gamma_{2}=\gamma_{3}=400$.

\section{Freguencies due to $\mathrm{CH}$ groups:}

$\gamma(\mathrm{CH})$ waving motions out of the plane of the molecule: (1016), 849(2), 671, and (985)(2).

$\delta(\mathrm{CH})$ waving motions in the plane of the molecule: (1298), 1178(2), (1170), and 1037(2).

$\mu(\mathrm{CH})$ stretching motions: $3062,3047(2), 3046$, and 3080(2). The frequencies in parentheses have not been observed because the vibrations to which they correspond are optically inactive. The benzene molecule is planar, a regular hexagon with distances between carbon atoms equal to
$1.39 \mathrm{~A}$ and distances between carbon and hydrogen atoms of $1.09 \mathrm{~A}$. The symmetry number is 12 . The principal moments of inertia about the center of mass are $292.9 \times 10^{-40} \mathrm{~g} \mathrm{~cm}^{2}, 146.5 \times 10^{-40}$ $\mathrm{g} \mathrm{cm}^{2}$, and $146.5 \times 10^{-40} \mathrm{~g} \mathrm{~cm}^{2}$. Their product is $6.28 \times 10^{-114} \mathrm{~g}^{3} \mathrm{~cm}^{6}$.

Calculated values of thermodynamic functions and properties are given in tables 3 and 4 . The moderate departures of calculated values of $-\left(F^{\circ}-E^{\circ}{ }_{0}\right) / T, H^{\circ}-E^{\circ}{ }_{0}$, and $C^{\circ}{ }_{\mathrm{p}}^{\circ}$ from those of reference [6] are thought to be due to the use of the latest values for the fundamental physical constants in the present calculations. The source of the value for $E^{\circ}{ }_{0}$ used in this paper is given in section XII.

Table values of $C^{\circ}$ are in agreement to within experimental accuracy with values of $C^{\circ}$ p derived from the calorimetrically measured heat capacities, which extend over the range $360^{\circ}$ to $480^{\circ} \mathrm{K}$. This may be seen in figure 7 in the paper by Pitzer and Scott, since the sets of calculated values of $C^{\circ}{ }_{p}$ in the two papers are in agreement to within less than the experimental error. 
TABLE 3.- Heat capacity at constant pressure, heat content, and related quantities of benzene in the ideal gas state

$\left[E_{0}=24,000\right.$ cal mole-1]

\begin{tabular}{|c|c|c|c|c|}
\hline$T$ & $\frac{H^{\circ}-E_{0}^{\circ}}{T}$ & $H^{\circ}$ & ${ }^{\mathrm{a}} \Delta H^{\circ}$ & $C_{D}^{o}$ \\
\hline${ }^{\circ} K$ & $\begin{array}{c}\text { cal deg-1 } \\
\text { mole-1 }\end{array}$ & cal mole-1 & cal mole-1 & $\begin{array}{c}\text { cal deg-1 } \\
\text { mole-1 }\end{array}$ \\
\hline 298.16 & 11.41 & 27,400 & 19,820 & 19.51 \\
\hline 300.00 & 11.46 & 27,440 & 19,800 & 19.65 \\
\hline 400 & 14.41 & 29,760 & 18,550 & 26. 74 \\
\hline 500 & 17.50 & 32,750 & 17,540 & 32.80 \\
\hline 600 & 20.48 & 36,290 & 16,720 & 37.74 \\
\hline 700 & 23.24 & 40,270 & 16,070 & 41.75 \\
\hline 800 & 25.76 & 44,610 & 15,570 & 45.06 \\
\hline 900 & 28.07 & 49,260 & 15,170 & 47.82 \\
\hline 1,000 & 30.16 & 54,160 & 14,880 & 50.16 \\
\hline 1,100 & 32.07 & 59,280 & 14,680 & 52.15 \\
\hline 1,200 & 33.82 & 64,580 & 14,550 & 53.85 \\
\hline 1,300 & 35.42 & 70,040 & 14,490 & 55.31 \\
\hline 1,400 & 36.88 & 75,640 & 14,490 & 56.57 \\
\hline 1,500 & 38.23 & 81,350 & 14,500 & 57.66 \\
\hline
\end{tabular}

$\Delta \Delta H^{\circ}$ is the enthalpy of formation of benzene from its elements in their standard states at the temperature $T$.
TABLE 4.-Entropy, free energy and related quantities of benzene in the ideal gas state at 1-atmosphere pressure

[E : $=24,000 \mathrm{cal} \mathrm{mole}^{-1}$ ]

\begin{tabular}{|c|c|c|c|c|c|}
\hline$T$ & $-\left(\frac{F^{\circ}-E_{0}^{\circ}}{T}\right)$ & $S^{\circ}$ & $-F^{\circ}$ & ${ }^{a} \Delta F^{\circ}$ & ${ }^{a} \log _{10} K$ \\
\hline & cal deg -1 & cal deg ${ }^{-1}$ & & & $-\underline{\Delta} F^{\circ} / R T$ \\
\hline${ }^{\circ} K$ & mole ${ }^{-1}$ & mole -1 & cal mole -1 & cal mole -1 & 2. 3026 \\
\hline 298.16 & 52.94 & 64.34 & $-8,220$ & 31,000 & -22.725 \\
\hline 300.00 & 53.01 & 64.46 & $-8,100$ & 31,070 & -22.634 \\
\hline 400 & 56.70 & 71.10 & $-1,320$ & 35,020 & -19.132 \\
\hline 500 & 60.25 & 77.74 & $+6,120$ & 39,260 & -17.161 \\
\hline 600 & 63.70 & 84.18 & 14,220 & 43,680 & -15.910 \\
\hline 700 & 67.07 & 90.31 & 22,950 & 48,230 & -15.058 \\
\hline 800 & 70.34 & 96.10 & 32,270 & 52,860 & -14.442 \\
\hline 900 & 73.51 & 101.57 & 42,160 & 57,550 & -13.975 \\
\hline 1,000 & 76.58 & 106. 74 & 52,580 & 62,270 & -13.610 \\
\hline 1,100 & 79.54 & 111.61 & 63,490 & 67,020 & -13.315 \\
\hline 1,200 & 82.41 & 116. 23 & 74,890 & 71,790 & -13.074 \\
\hline 1,300 & 85.18 & 120.60 & 86,730 & 76,550 & -12.869 \\
\hline 1,400 & 87.86 & 124.74 & 99,000 & 81,320 & -12.695 \\
\hline 1,500 & 90.45 & 128.68 & 111,670 & 86,100 & -12.545 \\
\hline
\end{tabular}

a $\Delta F^{\circ}$ and $K$ are the free-energy change and equilibrium constant, respectively, for the reaction forming benzene from its elements in their standard states at $T^{\circ} \mathrm{K}$.

\section{Cyclohexane}

The frequency assignment used in the calculations for cyclohexane is essentially the same as one given previously [7]. A value of $673 \mathrm{~cm}^{-1}$, which was used in a previous form of this paper for one frequency, has now been replaced by $864 \mathrm{~cm}^{-1}$ on the ground that the band reported at $673 \mathrm{~cm}^{-1}$ was due to an impurity. ${ }^{6}$ The molecule has a chair form with $D_{3 \mathrm{a}}$ symmetry, for which the symmetry number is 6 . The frequencies in $\mathrm{cm}^{-1}$ used were as follows:

\section{Carbon skeleton frequencies:}

Vibrations essentially parallel to the $\sigma_{z}$ plane: $\omega_{1}=\omega_{2}=425, \omega_{3}=864, \omega_{4}=801, \omega_{5}=\omega_{6}=1050$, $\omega_{7}=\omega_{8}=1266$, and $\omega_{9}=1370$.

Vibrations essentially parallel to the principal axis $\left[C_{3}\right]$ of the molecule: $\gamma_{1}=\gamma_{2}=196$ and $\gamma_{3}=377$.

\section{Frequencies due to $\mathrm{CH}_{2}$ groups:}

$\gamma\left(\mathrm{CH}_{2}\right)$ waving motions: $885(6), 1028(6)$, and $1345(6)$.

$\delta(\mathrm{HCH})$ bending motions: $1300(6)$.

$\nu(\mathrm{CH})$ stretching motions: $2770(12)$.

The frequency of the optically inactive, and doubly degenerate, rocking motion of the carbon skeleton, $\gamma_{1}=\gamma_{2}$, was calculated from the calorimetrically determined entropy [8] by using the assignments given here for the remaining frequencies.

\footnotetext{
- A private communication from E. K. Plyler, of the Radiometry Section of the National Bureau of Standards, indicates that there is no evidence for a band at $673 \mathrm{~cm}^{-1}$ when a very pure sample of cyclohexane is used.
}

The distance between carbon atoms was taken as $1.54 \mathrm{~A}$ and between carbon and hydrogen atoms as $1.09 \mathrm{~A}$. Using tetrahedral angles, the principal moments of inertia are $335.1 \times 10^{-40} \mathrm{~g} \mathrm{~cm}^{2}, 193.8 \times$ $10^{-40} \mathrm{~g} \mathrm{~cm}^{2}$, and $193.8 \times 10^{-40} \mathrm{~g} \mathrm{~cm}^{2}$, giving for the product of the three $12.58 \times 10^{-114} \mathrm{~g}^{3} \mathrm{~cm}^{6}$.

Tables 5 and 6 give the calculated values of

TABLE 5.-Heat capacity and constant pressure, heat content, and related quanities of cyclohexane in the ideal gas state

$\left[E_{0}^{\circ}=19,950\right.$ cal mole-1]

\begin{tabular}{|c|c|c|c|c|}
\hline$T$ & $\frac{H^{\circ}-E_{0}^{\circ}}{T}$ & $H^{\circ}$ & $\mathrm{a} \Delta H^{\circ}$ & $C_{p}^{\circ}$ \\
\hline${ }^{\circ} K$ & $\begin{array}{c}\text { cal deg-1 } \\
\text { mole }^{-1}\end{array}$ & cal mole-1 & cal mole-1 & $\underset{\text { mole }}{\text { cal } \text { deg }^{-1}}$ \\
\hline 298.16 & 14.13 & $-15,740$ & $-29,380$ & 25.15 \\
\hline 300.00 & 14. 20 & $-15,690$ & $-29,440$ & 25.35 \\
\hline 400 & 18. 31 & $-12,630$ & $-32,030$ & 35.87 \\
\hline 500 & 22.80 & $-8,550$ & $-34,050$ & 45.42 \\
\hline 600 & 27.26 & $-3,590$ & $-35,550$ & 53.45 \\
\hline 700 & 31.50 & $+2,100$ & $-36,590$ & 60.15 \\
\hline 800 & 35.44 & 8,400 & $-37,260$ & 65.77 \\
\hline 900 & 39.08 & 15,220 & $-37,610$ & 70.50 \\
\hline 1,000 & 42.43 & 22,480 & $-37,700$ & 74.51 \\
\hline 1,100 & 45.50 & 30,100 & $-37,580$ & 77.92 \\
\hline 1,200 & 48. 33 & 38,040 & $-37,270$ & 80.82 \\
\hline 1,300 & 50.93 & 46,250 & $-36,820$ & 83.30 \\
\hline 1,400 & 53. 31 & 54,690 & $-36,250$ & 85.42 \\
\hline 1,500 & 55.52 & 63,330 & $-35,610$ & 87.26 \\
\hline
\end{tabular}

- $\Delta H^{\circ}$ is the enthalpy of formation of cyclohexane from its elements in their standard states at the temperature $T$. 
TABLE 6.-Entropy, free energy, and related quantities of cyclohexane in the ideal gas state at 1-atmosphere pressure

$\left[E_{0}^{0}=19,950 \mathrm{cal} \mathrm{mole}^{-1}\right]$

\begin{tabular}{|c|c|c|c|c|c|}
\hline$T$ & $-\left(\frac{F^{\circ}-E_{0}^{\circ}}{T}\right)$ & $S^{c}$ & $-F^{\circ}$ & $\Delta F^{\circ}$ & ${ }^{8} \log _{10} K$ \\
\hline & cal deg-1 & cal deg-1 & & & $\Delta F^{\circ} / R T$ \\
\hline${ }^{\circ} \mathrm{K}$ & mole $e^{-1}$ & mole $^{-1}$ & cal mole-1 & cal mole ${ }^{-1}$ & 2.3026 \\
\hline 298.16 & 57.28 & 71.41 & 37,030 & 7,600 & -5.570 \\
\hline 300.00 & 57.37 & 71.57 & 37,160 & 7,830 & -5.703 \\
\hline 400 & 62.00 & 80.31 & 44,750 & 20,650 & -11.283 \\
\hline 500 & 66.57 & 89.37 & 53,230 & 34,070 & -14.894 \\
\hline 600 & 71.12 & 98.38 & 62,620 & 47,840 & -17.426 \\
\hline 700 & 75.64 & 107.14 & 72,900 & 61,830 & -19.305 \\
\hline 800 & 80.11 & 115.55 & 84,040 & 75,950 & -20.748 \\
\hline 900 & 84.50 & 123.58 & 96,000 & 90,120 & -21.884 \\
\hline 1,000 & 88.79 & 131.22 & 108,740 & 104,310 & -22.798 \\
\hline 1,100 & 92.98 & 138.48 & 122,230 & 118,510 & -23.545 \\
\hline 1,200 & 97.06 & 145.39 & 136,420 & 132,690 & -24.166 \\
\hline 1,300 & 101.03 & 151.96 & 151,290 & 146,820 & -24.683 \\
\hline 1,400 & 104.90 & 158.21 & 166,800 & 160,920 & -25.121 \\
\hline 1,500 & 108.65 & 164.17 & 182,930 & 175,000 & -25.498 \\
\hline
\end{tabular}

$\Delta \Delta F^{\circ}$ and $K$ are the free-energy change and equilibrium constant, respectively, for the reaction forming cyclohexane from its elements in their standard states at $T^{\circ} \mathrm{K}$. thermodynamic functions and properties. Table 7 is a comparison of calculated values and the experimental values of $C_{p}^{\circ}$ of Montgomery and DeVries [8] and Bennewitz and Rossner [9].

In section XIV the calculated values for the equilibrium constant for the hydrogenation of benzene to cyclohexane are compared with experimental data. The agreement is considered satisfactory.

TABLE 7.-A comparison of the calculated and experimental values for the heat capacity of cyclohexane above $300^{\circ} \mathrm{K}$

\begin{tabular}{|c|c|c|c|}
\hline$T$ & $\begin{array}{c}C_{p}^{\circ} \text { (cal- } \\
\text { culated) }\end{array}$ & $\begin{array}{c}C_{p}^{\circ} \text { (experi- } \\
\text { mental) }\end{array}$ & Observers a \\
\cline { 1 - 3 } & $\begin{array}{c}\text { cal } \text { deg }^{-1} \\
\text { mole }^{-1}\end{array}$ & $\begin{array}{c}\text { cal deg-1 } \\
\text { mole }^{-1}\end{array}$ & \\
370 & 32.80 & 33.0 & $(8)$ \\
390 & 34.86 & 35.0 & $(8)$ \\
410 & 36.88 & 36.8 & $(8)$ \\
410 & 36.88 & 37.0 & $(9)$ \\
\hline
\end{tabular}

s(8) J. B. Montgomery and T. DeVries, (9) K. Bennewitz and W. Rossner,

\section{Ethane}

The frequency assignment used for ethane was taken from a paper by Stitt [10]. The frequencies in centimeters ${ }^{-1}$ were:

Frequency due to $\mathrm{C}-\mathrm{C}$ vibration:

$\omega=993$.

Frequencies due to $\mathrm{CH}_{3}$ vibrations:

$\gamma\left(\mathrm{CH}_{3}\right)$ rocking motions: $827(2)$ and $1170(2)$.

$\delta(\mathrm{HCH})$ bending motions: $1375,1380,1460(2)$, and $1465(2)$.

$\mu(\mathrm{C}-\mathrm{H})$ stretching motions: $2925(2), 2960(2)$, and $2980(2)$.

Stitt's value of $1,170 \mathrm{~cm}^{-1}$ for the "uncertain frequency" of ethane is based upon $D_{3 \mathrm{~d}}$ symmetry and an application of the product rule to the spectra of $\mathrm{C}_{2} \mathrm{H}_{6}$ and $\mathrm{C}_{2} \mathrm{D}_{6}$.

As Kemp and Pitzer [11] have shown and others have confirmed, there is a mode of hindered rotation corresponding to rotation of one methyl group with respect to the other. For low energies the motion is vibration, whereas for large energies it is complete rotation. The height used for the barrier, 2,750 cal $\mathrm{mole}^{-1}$, is the value determined by Kistiakowsky, Lacher, and Stitt [12] from low-temperature specific-heat measurement on gaseous ethane.

The ethane molecule has a symmetry number of six. With $1.54 \mathrm{~A}$ for the carbon-carbon distance and $1.09 \mathrm{~A}$ for the carbon-hydrogen distances, the principal moments of inertia are found to be $10.60 \times 10^{-40} \mathrm{~g} \mathrm{~cm}^{2}, 41.84 \times 10^{-40} \mathrm{~g} \mathrm{~cm}^{2}$, and $41.84 \times 10^{-40} \mathrm{~g} \mathrm{~cm}^{2}$, whereas the reduced moment for the internal rotation is $2.65 \times 10^{-40} \mathrm{~g} \mathrm{~cm}^{2}$. The product of the principal moments of inertia is $18.56 \times 10^{-117} \mathrm{~g}^{3} \mathrm{~cm}^{6}$.

The values calculated for the various thermodynamic functions of ethane are given in tables 8 and 9 .

Table 10 gives a comparison of calculated values of $C_{p}^{\circ}$ with experimental values based on the work of Thayer and Stegeman [13], Dailey and Felsing [14] and Eucken and Parts [15].

The calorimetric entropy, $S^{\circ}$, at $25^{\circ} \mathrm{C}$ is given by Witt and Kemp [16] as $54.85 \mathrm{cal} \mathrm{deg}^{-1} \mathrm{~mole}^{-1}$. The corresponding statistically calculated $S^{\circ}$ for $298.16^{\circ} \mathrm{K}$ is $54.83 \mathrm{cal} \mathrm{deg}^{-1} \mathrm{~mole}^{-1}$. 
TABLE 8.-Heat capacity at constant pressure, heat content, and related quantities of ethane in the ideal gas state

$\left[E_{0}^{0}=-16,520 \mathrm{cal} \mathrm{mole}^{-1}\right]$

\begin{tabular}{|c|c|c|c|c|}
\hline$T$ & $\frac{H^{\circ}-E_{0}^{\circ}}{T}$ & $H^{\circ}$ & $\Delta H^{\circ}$ & $C_{p}^{\circ}$ \\
\hline${ }^{\circ} \mathrm{K}$ & $\begin{array}{c}\text { cal deg-1 } \\
\text { mole }^{-1}\end{array}$ & cal mole-1 & cal mole -1 & $\begin{array}{c}\text { cal deg-1 } \\
\text { mole }^{-1}\end{array}$ \\
\hline 298.16 & 9.59 & $-13,660$ & $-20,240$ & 12. 59 \\
\hline 300.00 & 9.60 & $-13,640$ & $-20,260$ & 12.65 \\
\hline 400 & 10.73 & $-12,230$ & $-21,430$ & 15.68 \\
\hline 500 & 12.02 & $-10,510$ & $-22,440$ & 18.66 \\
\hline 600 & 13. 35 & $-8,510$ & $-23,290$ & 21.34 \\
\hline 700 & 14.67 & $-6,250$ & $-23,980$ & 23.71 \\
\hline 800 & 15.93 & $-3,780$ & $-24,530$ & 25.82 \\
\hline 900 & 17.13 & $-1,100$ & $-24,960$ & 27.68 \\
\hline 1,000 & 18.27 & $+1,750$ & $-25,280$ & 29. 31 \\
\hline 1,100 & 19. 34 & 4,750 & $-25,500$ & 30.75 \\
\hline 1,200 & 20.33 & 7,880 & $-25,650$ & 32.00 \\
\hline 1,300 & 21.27 & 11,130 & $-25,730$ & 33.10 \\
\hline 1,400 & 22.15 & 14,480 & $-25,760$ & 34. 05 \\
\hline 1,500 & 22.97 & 17,930 & $-25,750$ & 34.89 \\
\hline
\end{tabular}

- $\Delta H^{\circ}$ is the enthalpy of formation of ethane from its elements in their standard states at the temperature $T$.

TABLE 9.-Entropy, free energy, and related quantities of ethane in the ideal gas state at 1-atmosphere pressure [ $\left.E_{0}^{\circ}=-16,520 \mathrm{cal} \mathrm{mole}^{-1}\right]$

\begin{tabular}{|c|c|c|c|c|c|}
\hline$T$ & $\left(\frac{F^{\circ}-E_{0}^{\circ}}{T}\right)$ & $S^{\circ}$ & $-F^{\circ}$ & $\Delta F^{\circ}$ & ${ }^{2} \log _{10} K$ \\
\hline${ }^{\circ} \mathrm{K}$ & $\begin{array}{c}\text { cal deg } g^{-1} \\
\text { mole }^{-1}\end{array}$ & $\begin{array}{c}\text { cal deg-1 } \\
\text { mole-1 }\end{array}$ & cal mole-1 & cal mole-1 & $-\frac{F^{\circ} / R T}{2.3026}$ \\
\hline 298.16 & 45.25 & 54.83 & 30,010 & $-7,850$ & 5.756 \\
\hline 300.00 & 45.31 & 54.91 & 30,110 & $-7,780$ & 5.665 \\
\hline 400 & 48.22 & 58.95 & 35,810 & $-3,440$ & 1.880 \\
\hline 500 & 50.76 & 62.78 & 41,900 & $+1,180$ & -0.514 \\
\hline 600 & 53.07 & 66.42 & 48,360 & 5,980 & -2.179 \\
\hline 700 & 55.22 & 69.89 & 55,180 & 10,920 & -3.409 \\
\hline 800 & 57.27 & 73.20 & 62,330 & 15,940 & -4.356 \\
\hline 900 & 59.21 & 76.34 & 69,810 & 21,030 & -5.106 \\
\hline 1,000 & 61.08 & 79. 35 & 77,600 & 26,150 & -5.715 \\
\hline 1,100 & 62.87 & 82.21 & 85,680 & 31,310 & -6.220 \\
\hline 1,200 & 64.60 & 84.93 & 94,040 & 36,480 & -6.643 \\
\hline 1,300 & 66.27 & 87.54 & 102,670 & 41,650 & -7.001 \\
\hline 1,400 & 67.88 & 90.03 & 111,560 & 46,820 & -7.309 \\
\hline 1,500 & 69.44 & 92.41 & 120,680 & 52,010 & -7.577 \\
\hline
\end{tabular}

$\Delta F^{\circ}$ and $K$ are the free-energy change and equilibrium constant, respectively, for the reaction forming ethane from its elements in theirstandard states at $T^{\circ} \mathrm{K}$.
TABLE 10.-Comparison of the calculated and experimental values for the heat capacity of ethane in the ideal gas state (above $300^{\circ} \mathrm{K}$ )

\begin{tabular}{|c|c|c|c|}
\hline$T$ & $\begin{array}{c}C_{D}^{\circ} \\
\text { (calculated) }\end{array}$ & $\begin{array}{c}C_{p}^{\circ} \\
\text { (experimental) }\end{array}$ & Observers \\
\hline${ }^{\circ} K$ & $\underset{\text { mole }^{-1}}{\text { cal deg-1 }}$ & $\begin{array}{c}\text { cal deg-1 } \\
\text { mole }^{-1}\end{array}$ & \\
\hline 337.66 & 13. 78 & 13.3 & (13) \\
\hline 347.66 & 14.09 & 14.08 & (14) \\
\hline 359.76 & 14.46 & 14.43 & (14) \\
\hline 373.5 & 14.87 & 14.836 & (15) \\
\hline 373.6 & 14.88 & 14.842 & (15) \\
\hline 387.56 & 15.30 & 15.27 & (14) \\
\hline 451.96 & 17.26 & 17.31 & (14) \\
\hline 520.56 & 19.24 & 19.14 & (14) \\
\hline 561.66 & 20.36 & 20.62 & (14) \\
\hline 603.26 & 21.42 & 21.62 & (14) \\
\hline
\end{tabular}

-(13) V. R. Thayer and G. Stegeman, (14) B. P. Dailey and W. A. Felsing, (15) A. Eucken and A. Parts.

\section{Ethylene}

The fundamental frequencies used for ethylene are those given by Galloway and Barker [17]. The frequencies in centimeters ${ }^{-1}$ are:

Frequency due to $\mathrm{C}=\mathrm{C}$ vibration:

\section{3}

Frequencies due to $\mathrm{CH}_{2}$ vibrations:

$\gamma(\mathrm{C}-\mathrm{H})$ rocking motions: 995, 1055, 949.2, 950 , and 825 .
$\delta(\mathrm{HCH})$ bending motions: 1342.4 and 1443.9 . $\mu(\mathrm{C}-\mathrm{H})$ stretching motions: $3019.3,2989.5$, 3105.5 , and 3069 . The frequency $825 \mathrm{~cm}^{-1}$ corresponds to the torsional twist of the $\mathrm{C}=\mathrm{C}$ bond.

The molecule is planar and has a symmetry number of 4 . The principal moments of inertia derived from the ethylene spectra by Galloway and Barker were used. They are $33.84 \times 10^{-40} \mathrm{~g} \mathrm{~cm}^{2}$, 
$28.09 \times 10^{-40} \mathrm{~g} \mathrm{~cm}$, and $5.750 \times 10^{-40} \mathrm{~g} \mathrm{~cm}^{2}$. Their product is $5.466 \times 10^{-117} \mathrm{~g}^{3} \mathrm{~cm}^{6}$. The thermodynamic functions for ethylene are given in tables 11 and 12.

In table 13 the calculated values of $C^{\circ}{ }_{p}$ are compared with the experimental values from the work of Haas and Stegeman [18], Burcik, Eyster, and Yost [19] and Eucken and Parts [15].

The calorimetric entropy, $S^{\circ}$, at $25^{\circ} \mathrm{C}$, is given by Egan and Kemp [20] as $52.48 \mathrm{cal} \mathrm{deg}^{-1} \mathrm{~mole}^{-1}$. The corresponding statistically calculated $S^{\circ}$ for $298.16^{\circ} \mathrm{K}$ is $52.454 \mathrm{cal} \mathrm{deg}^{-1}$ mole $^{-1}$.

TABLE 11.-Heat capacity at constant pressure, heat conient and related quantities of ethylene in the ideal gas state

$\left[E_{0}^{\circ}=14,530 \mathrm{cal} \mathrm{mole}^{-1}\right]$

\begin{tabular}{|c|c|c|c|c|}
\hline$T$ & $\frac{H^{\circ}-E_{0}^{\circ}}{T}$ & $H^{\circ}$ & a $\Delta H^{\circ}$ & $C_{p}^{\circ}$ \\
\hline${ }^{\circ} K$ & $\begin{array}{c}\text { cal deg-1 } \\
\text { mole }\end{array}$ & cal mole-1 & cal mole-1 & $\begin{array}{c}\text { cal deg-1 } \\
\text { mole }{ }^{-1}\end{array}$ \\
\hline 298.16 & 8.47 & 17,060 & 12,510 & 10.41 \\
\hline 300.00 & 8.49 & 17,080 & 12,490 & 10.46 \\
\hline 400 & 9.28 & 18,240 & 11,780 & 12.91 \\
\hline 500 & 10.24 & 19,650 & 11,150 & 15. 18 \\
\hline 600 & 11. 23 & 21,270 & 10,610 & 17.12 \\
\hline 700 & 12. 19 & 23,070 & 10,170 & 18. 78 \\
\hline 800 & 13.11 & 25,020 & 9,800 & 20.23 \\
\hline 900 & 13.97 & 27,110 & 9,490 & 21.49 \\
\hline 1,000 & 14. 78 & 29,310 & 9,250 & 22.60 \\
\hline 1,100 & 15.54 & 31,620 & 9,060 & 23. 58 \\
\hline 1,200 & 16. 25 & 34,020 & 8,920 & 24.43 \\
\hline 1,300 & 16.90 & 36,500 & 8,810 & 25.18 \\
\hline 1,400 & 17.52 & 39,050 & 8,740 & 25.83 \\
\hline 1,500 & 18.09 & 11,670 & 8,690 & 26.41 \\
\hline
\end{tabular}

${ }^{a} \Delta H^{\circ}$ is the enthalpy of formation of ethylene from its elements in their standard states at the temperature $T$.
TABLE 12.-Entropy, free energy, and related quantities of ethylene in the ideal gas state at 1-atmosphere pressure

$\left[E_{0}^{*}=14,530 \mathrm{cal} \mathrm{mole}^{-1}\right]$

\begin{tabular}{|c|c|c|c|c|c|}
\hline$T$ & $\left(\frac{F^{\circ}-E_{0}^{\circ}}{T}\right)$ & $S^{\circ}$ & $-F^{\circ}$ & $\Delta F^{\circ}$ & ${ }^{a} \log _{10} K$ \\
\hline${ }^{\circ} K$ & $\underset{\text { mole }}{\text { cal deg-1 }}$ & $\begin{array}{c}\text { cal } \text { deg }^{-1} \\
\text { mole }^{-1}\end{array}$ & $\underset{\text { mole }}{c a l}$ & $\underset{c a l}{c a l e^{-1}}$ & $\frac{-\Delta F^{\circ} / R T}{2.3026}$ \\
\hline 298.16 & 43.98 & 52.45 & $-1,420$ & 16,290 & -11.943 \\
\hline 300.00 & 44.03 & 52.52 & $-1,320$ & 16,320 & -11.887 \\
\hline 400 & 46.58 & 55.86 & $+4,100$ & 17,700 & -9.670 \\
\hline 500 & 48.75 & 58.99 & 9,850 & 19,260 & -8.417 \\
\hline 600 & 50.71 & 61.94 & 15,890 & 20,930 & -7.613 \\
\hline 700 & 52.51 & 64.70 & 22,230 & 22,680 & -7.082 \\
\hline 800 & 54.20 & 67.31 & 28,830 & 24,500 & -6.693 \\
\hline 900 & 55.79 & 69.76 & 35,680 & 26,350 & -6.400 \\
\hline 1,000 & 57.31 & 72.09 & 42,780 & 28,240 & -6.172 \\
\hline 1,100 & 58.75 & 74.29 & 50,100 & 30,150 & -5.990 \\
\hline 1,200 & 60.13 & 76.38 & 57,630 & 32,070 & -5.841 \\
\hline 1,300 & 61.46 & 78.36 & 65,370 & 34,000 & -5.717 \\
\hline 1,400 & 62.73 & 80.25 & 73,300 & 35,940 & -5.611 \\
\hline 1,500 & 63.96 & 82.05 & 81,420 & 37,890 & -5.520 \\
\hline
\end{tabular}

${ }^{a} \Delta F^{\circ}$ and $K$ are the free-energy change and equilibrium constant, respectively, for the reaction forming ethylene from its elements in their standard states at $T^{\circ} \mathrm{K}$.

TABLE 13.-Comparison of the calculated and experimental values for the heat capacity of ethylene in the ideal gas state above $300^{\circ} \mathrm{K}$

\begin{tabular}{|c|c|c|c|}
\hline$T$ & $\begin{array}{c}C_{p}^{\circ} \\
\text { (calculated) }\end{array}$ & $\begin{array}{c}C_{p}^{\circ} \\
\text { (experimental) }\end{array}$ & Observers * \\
\cline { 2 - 4 } & $\begin{array}{c}\text { cal deg-1 } \\
\text { mole }{ }^{-1}\end{array}$ & $\begin{array}{c}\text { cal deg-1 } \\
\text { mole-1 }\end{array}$ & \\
\hline${ }^{\circ} K$ & 10.41 & 9.97 & $(18)$ \\
298.16 & 10.98 & 10.40 & $(18)$ \\
319.16 & 11.46 & 10.98 & $(18)$ \\
339.96 & 10.46 & 10.39 & $(19)$ \\
300.0 & 11.00 & 10.99 & $(19)$ \\
320.7 & & & \\
368.2 & 12.15 & 11.897 & $(15)$ \\
464.0 & 14.39 & 14.16 & $(15)$ \\
\hline
\end{tabular}

a (18) M. E. Haas and G. Stegeman, (19) E. J. Burcik, E. H. Eyster and D. M. Yost, (15) A. Eucken and A. Parts.

\section{Acetylene}

For acetylene, the thermodynamic functions used are those given in a recent paper by Wagman, Kilpatrick, Pitzer, and Rossini [21]. Their values are based largely upon an assignment by $\mathrm{Wu}$ [22] and include the effects of anharmonicity, rota- tional-vibrational coupling, rotational stretching, and an Euler-Maclaurin series summation correction term. They have been used in preference to our earlier tables, which were based on a table by Gordon [23]. 


\section{Ethyl Alcohol}

The thermodynamic functions for ethyl alcohol are given in tables 14 and 15 . The frequency assignment used in the calculations of these tables agrees closely with one previously given [24, 25]. The value of $700 \mathrm{~cm}^{-1}$, there assigned to the $\mathrm{COH}$ angle frequency, was based on earlier papers on methyl alcohol. For the $\mathrm{COH}$ angle vibration in methyl alcohol, Borden and Barker [26] later suggested a frequency of $1,030 \mathrm{~cm}^{-1}$, and most recently Noether [27] assigned the frequency 1,340 $\mathrm{cm}^{-1}$. For the calculations of tables 14 and 15 the observed [28] Raman frequency $1,274 \mathrm{~cm}^{-1}$ of ethyl alcohol has been assigned to the $\mathrm{COH}$ vibration. To the internal bending vibration of the $\mathrm{CH}_{2}$ group has been assigned the observed Raman frequency $1,455 \mathrm{~cm}^{-1}$. Others of the observed Raman frequencies in addition to those listed by Bolla as fundamentals have here been chosen as fundamentals because of their approximate equality with frequencies for similar motions in propane given in the assignment of V. L. Wu and E. F. Barker [29]. Thus the frequencies in centimeters ${ }^{-1}$ that have been used are:

\section{C-C-O skeleton frequencies:}

883, 1096, and 433.

Frequencies due to $\mathrm{CH}_{3}$ vibrations:

$\gamma\left(\mathrm{CH}_{3}\right)$ rocking motions: 814 and 1051 .

$\nu(\mathrm{C}-\mathrm{H})$ stretching motions: $2930(3)$.

$\delta(\mathrm{HCH})$ bending motions: 1387 and 1455(2).

TABLE 14.-Heat capacity at constant pressure, heat content, and related quantities of ethyl alcohol in the ideal gas state

$\left[E_{0}^{\circ}=-52,260 \mathrm{cal} \mathrm{mole}^{-1}\right]$

\begin{tabular}{|c|c|c|c|c|}
\hline$T$ & $\frac{H^{\circ}-E_{0}^{\circ}}{T}$ & $H^{\circ}$ & $\Delta H^{\circ}$ & $C_{p}^{\circ}$ \\
\hline${ }^{\circ} K$ & $\begin{array}{c}\text { cal deg-1 } \\
\text { mole }^{-1}\end{array}$ & cal mole-1 & cal mole-1 & $\underset{\text { mole }^{-1}}{\text { cal deg-1 }}$ \\
\hline 298.16 & 12.18 & $-48,630$ & $-56,240$ & 17. 59 \\
\hline 300.00 & 12. 22 & $-48,600$ & $-56,260$ & 17. 66 \\
\hline 400 & 14.00 & $-46,660$ & $-57,250$ & 21.00 \\
\hline 500 & 15.70 & $-44,410$ & $-58,110$ & 24.09 \\
\hline 600 & 17.33 & $-41,860$ & $-58,780$ & 26.81 \\
\hline 700 & 18.86 & $-39,060$ & $-59,320$ & 29.18 \\
\hline 800 & 20.28 & $-36,030$ & $-59,710$ & 31. 25 \\
\hline 900 & 21.61 & $-32,810$ & $-60,000$ & 33.07 \\
\hline 1,000 & 22.83 & $-29,430$ & $-60,200$ & 34.66 \\
\hline 1,100 & 23.97 & $-25,900$ & $-60,320$ & 36.06 \\
\hline 1,200 & 25.02 & $-22,240$ & $-60,370$ & 37.28 \\
\hline 1,300 & 25.99 & $-18,470$ & $-60,350$ & 38.34 \\
\hline 1,400 & 26.91 & $-14,590$ & $-60,250$ & 39.27 \\
\hline 1,500 & 27.75 & $-10,630$ & $-60,190$ & 40.08 \\
\hline
\end{tabular}

- $\Delta H^{\circ}$ is the enthalpy of formation of ethyl alcohol from its elements in their standard states at the temperature $T$.
TABLE 15.-Entropy, free energy, and related quantities of ethyl alcohol in the ideal gas state at 1-atmosphere pressure

$\left[E_{0}^{\circ}=-52,260 \mathrm{cal} \mathrm{mole}^{-1}\right]$

\begin{tabular}{|c|c|c|c|c|c|}
\hline$T$ & $-\left(\frac{F^{\circ}-E_{0}^{\circ}}{T}\right)$ & $S^{\circ}$ & $-F^{\circ}$ & $a \Delta F^{\circ}$ & $a_{\log } 10 K$ \\
\hline${ }^{\circ} \mathrm{K}$ & $\begin{array}{c}\text { cal deg-1 } \\
\text { mole } e^{-1}\end{array}$ & $\begin{array}{c}\text { cal deg-1 } \\
\text { mole }^{-1}\end{array}$ & cal mole-1 & cal mole-1 & $\frac{-\Delta F^{\circ} / R T}{2.3026}$ \\
\hline 298. 16 & 54. 27 & 66. 45 & 68,440 & $-40,010$ & 29.329 \\
\hline 300.00 & 54.34 & 66.56 & 68,560 & $-39,910$ & 29.075 \\
\hline 400 & 58.11 & 72.11 & 75,500 & $-34,310$ & 18.749 \\
\hline 500 & 61.42 & 77.12 & 82,970 & $-28,470$ & 12.447 \\
\hline 600 & 64.43 & 81.76 & 90,920 & $-22,490$ & 8.191 \\
\hline 700 & 67.22 & 86.08 & 99,310 & $-16,390$ & 5.118 \\
\hline 800 & 69.84 & 90.12 & 108,130 & $-10,230$ & 2.796 \\
\hline 900 & 72.31 & 93.92 & 117,330 & $-4,030$ & 0.980 \\
\hline 1,000 & 74. 65 & 97.48 & 126,910 & $+2,190$ & -0.479 \\
\hline 1,100 & 76.88 & 100.85 & 136,830 & 8,430 & -1.675 \\
\hline 1,200 & 79.02 & 104.04 & 147,080 & 14,680 & -2.673 \\
\hline 1,300 & 81.07 & 107.06 & 157,650 & 20,920 & -3.517 \\
\hline 1,400 & 83.03 & 109.94 & 168,500 & 27,170 & -4.239 \\
\hline 1,500 & 84.92 & 112.67 & 179,640 & 33,410 & -4.867 \\
\hline
\end{tabular}

- $\Delta F^{\circ}$ and $K$ are the free-energy change and equilibrium constant, respectively, for the reaction forming ethyl alcohol from its elements in their standard states at $T^{\circ} \mathrm{K}$.

Frequencies due to $\mathrm{CH}_{2}$ vibrations:

$\gamma\left(\mathrm{CH}_{2}\right)$ waving motions: 814, 1125, and 1160 .

$\nu(\mathrm{C}-\mathrm{H})$ stretching motions: $2930(2)$.

$\delta(\mathrm{HCH})$ bending motion: 1455.

Frequencies due to $\mathrm{OH}$ vibrations:

$\gamma(\mathrm{O}-\mathrm{H})$ stretching motion: 3359 .

$\delta(\mathrm{COH})$ bending motion: 1274 .

The barriers restricting the internal rotations of ethyl alcohol have recently been estimated [30] by a method involving a correlation of known barrier heights in various compounds. According to this calculation, there is a barrier of $1,800 \mathrm{cal} \mathrm{mole}^{-1}$ for the methyl group for the straight form of the molecule, that is, the form in which the $\mathrm{OH}$ group is in a plane of symmetry of the molecule, and $3,000 \mathrm{cal} \mathrm{mole}^{-1}$ for the bent forms, in which the $\mathrm{H}$ of the $\mathrm{OH}$ group is on either side of the plane and about $104^{\circ}$ from its straight position. The barrier heights for the hydroxyl group are more complicated. For the methyl group in a position of minimum energy the calculated potential energy of the hydroxyl group ranges from zero for the straight form to a maximum of $2,375 \mathrm{cal} \mathrm{mole} \mathrm{c}^{-1}$ when the $\mathrm{OH}$ group has rotated about $65^{\circ}$, to a minimum of $1,560 \mathrm{cal} \mathrm{mole^{-1 }}$ at $104^{\circ}$, to another maximum of 5,970 cal mole ${ }^{-1}$ at $180^{\circ}$, in which 
position the $\mathrm{OH}$ group extends toward the methyl group.

The calculations of the thermodynamic functions with these data on the barriers restricting rotation have been made by using a natural extension of Pitzer's [31] steric factor method for barriers with different minimal and maximal values.

With 1.54 A for the C-C distance, 1.09 A for the $\mathrm{C}-\mathrm{H}$ distances, $1.42 \mathrm{~A}$ for the $\mathrm{C}-\mathrm{O}$ distance, $0.96 \mathrm{~A}$ for the $\mathrm{O}-\mathrm{H}$ distance, $105^{\circ}$ for the $\mathrm{C}-\mathrm{O}-\mathrm{H}$ angle and tetrahedral angles for all other angles, the product of the three principal moments of inertia is found to be $2.249 \times 10^{-115} \mathrm{~g}^{3} \mathrm{~cm}^{6}$ for the molecule in the straight form and $2.292 \times 10^{-115} \mathrm{~g}^{3}$ $\mathrm{cm}^{6}$ for the molecule in the bent form. The reduced moment of inertia for the $\mathrm{CH}_{3}$ group is $4.83 \times 10^{-40} \mathrm{~g} \mathrm{~cm}^{2}$ and for the $\mathrm{OH}$ group is $1.40 \times 10^{-40}$ $\mathrm{g} \mathrm{cm}^{2}$. In table 16 the calculated values of $C_{p}^{\circ}$ are compared with the experimental values by Dixon and Greenwood [32], Jatkar [33], Bennewitz and Rossner [9], and Regnault [34], The calculated values are higher than the experimental values except for the value of Regnault at $623^{\circ} \mathrm{K}$. This one value may be doubted because of its antiquity and the experimental difficulties at the elevated temperature. It is entirely possible that the present treatment will require revision when more accurate experimental values of the specific heat are available.

TABLE 16.-Comparison of the calculated and experimental values for the heat capacity of ethyl alcohol in the ideal gas state

\begin{tabular}{|c|c|c|c|}
\hline$T$ & $\begin{array}{c}C_{p}^{\circ} \\
\text { (calculated) }\end{array}$ & $\begin{array}{c}C_{p}^{\circ} \\
\text { (experimental) }\end{array}$ & Observers a \\
\hline & $\begin{array}{c}\text { cal deg-1 }^{-1} \\
\text { mole }^{-1}\end{array}$ & $\begin{array}{c}\text { cal deg-1 }^{-1} \\
\text { mole }^{-1}\end{array}$ & \\
363.16 & 19.76 & 18.49 & $(32)$ \\
370.26 & 20.00 & 19.86 & $(33)$ \\
407.16 & 21.24 & 18.75 & $(33)$ \\
410.16 & 21.34 & 19.6 & $(9)$ \\
437.16 & 22.20 & 20.8 & $(34)$ \\
623.16 & 27.38 & 28.2 & $(34)$ \\
\hline
\end{tabular}

- (32) H. B. Dixon and G. Greenwood, (33) S. K. K. Jatkar, (9) K. Bennewitz and W. Rossner, (34) H. V. Regnault.

The entropy, $S^{\circ}$, at the boiling point, $351.5^{\circ} \mathrm{K}$, based on calorimetric measurements below $298.16^{\circ}$ $\mathrm{K}$ by Kelley [35] and at higher temperatures by Fiock, Ginnings, and Holton [36] is $69.7 \mathrm{cal} \mathrm{deg}^{-1}$ mole $^{-1}$. The value interpolated from table 15 is $69.42 \mathrm{cal} \mathrm{deg}^{-1}$ mole $^{-1}$, agreeing to the uncertainty of the calorimetric value. A similarly obtained calorimetric value of $S^{\circ}$ at $403.2^{\circ} \mathrm{K}$ is $72.1 \mathrm{cal} \mathrm{deg}^{-1} \mathrm{~mole}^{-1}$, while the corresponding value from table 15 is $72.28 \mathrm{cal} \mathrm{deg}^{-1} \mathrm{~mole}^{-1}$.

\section{Water}

The thermodynamic functions of table 17 and 18 for water are based on tables published by Gordon [37]. Gordon took into account the anharmonicities of the $\mathrm{H}_{2} \mathrm{O}$ vibrations. For the tables of this paper Gordon's values have been adjusted for rotational stretching by using Wilson's theory [38], with a value of the stretching constant determined by Stephenson and McMahon [39]. An adjustment for the change in the generally accepted values of the fundamental physical constants has also been made.

The entropy, $S^{\circ}$, of water at $25^{\circ} \mathrm{C}$, was given by Giauque and Archibald [40] as $45.10 \mathrm{cal} \mathrm{deg}^{-1}$ mole $^{-1}$ on the basis of an investigation of the equilibrium of $\mathrm{MgO}, \mathrm{Mg}(\mathrm{OH})_{2}$, and $\mathrm{H}_{2} \mathrm{O}$, and the calorimetrically determined entropies of $\mathrm{MgO}$ and $\mathrm{Mg}(\mathrm{OH})_{2}$. The value from table 18 is $45.109 \mathrm{cal} \mathrm{deg}^{-1} \mathrm{~mole}^{-1}$ at $298.16^{\circ} \mathrm{K}$. 
TABLE 17.-Heat capacity at constart pressure, heat content, and related quantities of water in the ideal gas state

$\left[E_{0}^{*}=-57,106 \mathrm{cal} \mathrm{mole}^{-1}\right]$

\begin{tabular}{|c|c|c|c|c|}
\hline$T$ & $\frac{H^{\circ}-E_{0}^{\circ}}{T}$ & $H^{\circ}$ & $\triangle H^{\circ}$ & $C_{\mathrm{D}}^{\circ}$ \\
\hline${ }^{\circ} \mathrm{K}$ & cal deg-1 mole-1 & cal mole-1 & cal mole-1 & cal deg ${ }^{-1}$ mole $^{-1}$ \\
\hline 298.16 & 7.934 & $-54,740$ & $-57,799$ & 8. 028 \\
\hline 300.00 & 7.935 & $-54,725$ & $-57,803$ & 8.030 \\
\hline 400 & 7.977 & $-53,915$ & $-58,042$ & 8.190 \\
\hline 500 & 8.041 & $-53,085$ & $-58,276$ & 8.421 \\
\hline 600 & 8. 125 & $-52,231$ & $-58,500$ & 8.685 \\
\hline 700 & 8. 226 & $-51,347$ & $-58,707$ & 8.968 \\
\hline 800 & 8. 338 & $-50,436$ & $-58,900$ & 9.264 \\
\hline 900 & 8.456 & $-49,495$ & $-59,077$ & 9.570 \\
\hline 1,000 & 8.586 & $-48,520$ & $-59,234$ & 9.881 \\
\hline 1,100 & 8.715 & $-47,520$ & $-59,379$ & 10.185 \\
\hline 1,200 & 8.851 & $-46,486$ & $-59,506$ & 10.480 \\
\hline 1,300 & 8.988 & $-45,422$ & $-59,615$ & 10.763 \\
\hline 1,400 & 9.125 & $-44,333$ & $-59,715$ & 11.031 \\
\hline 1,500 & 9.260 & $-43,217$ & $-59,801$ & 11.279 \\
\hline
\end{tabular}

- $\triangle H^{\circ}$ is the enthalpy of formation of water from its elements in their standard states at the temperature $T$.
TABLE 18.-Entropy, free energy and related quantities of water in the ideal gas state at 1-atmosphere pressure

$\left[E_{0}^{\circ}=-57,106\right.$ cal mole $\left.^{-1}\right]$

\begin{tabular}{|c|c|c|c|c|c|}
\hline$T$ & $\left(\frac{F^{\circ}-E_{0}^{\circ}}{T}\right)$ & $S^{\circ}$ & $-F^{\circ}$ & $\triangle F^{\circ}$ & a $\log _{10} K$ \\
\hline${ }^{\circ} \mathrm{K}$ & $\underset{\text { mole }^{-1}}{\text { cal deg-1 }}$ & $\begin{array}{c}\text { cal deg-1 } \\
\text { mole }^{-1}\end{array}$ & cal mole & -1 cal mole-1 & $\frac{-\Delta F^{\circ} / R T}{2.3026}$ \\
\hline 298.16 & 37.175 & 45. 109 & 68,190 & $-54,638$ & 10.050 \\
\hline 300.00 & 37. 224 & 45. 159 & 68,273 & $-54,618$ & 39. 790 \\
\hline $400 \ldots$ & 39.512 & 47.489 & 72,911 & $-53,521$ & 29.243 \\
\hline 500 & 41. 299 & 49. 340 & 77,756 & $-52,363$ & 22.888 \\
\hline $600 \ldots$ & 42.773 & 50.898 & 82,770 & $-51,160$ & 18.635 \\
\hline 700 & 44. 032 & 52. 258 & 87,928 & $-49,918$ & 15. 585 \\
\hline $800 \ldots$ & 45.137 & 53. 475 & 93,216 & $-48,648$ & 13. 290 \\
\hline 900 & 46.127 & 54. 583 & 98,620 & $-47,357$ & 11.500 \\
\hline $1,000 \ldots$ & 47.023 & 55. 609 & 104,129 & $-46,046$ & 10.063 \\
\hline 1,100 & 47.849 & 56.564 & 109,740 & $-44,722$ & 8.886 \\
\hline $1,200 \ldots$ & 48. 612 & 57.463 & 115,440 & $-43,381$ & 7. 901 \\
\hline $1,300_{\ldots}$ & 49.326 & 58.314 & 121,230 & $-42,036$ & 7. 067 \\
\hline $1,400 \ldots$ & 49. 997 & 59.122 & 127,102 & $-40,681$ & 6. 351 \\
\hline 1,500 & 50.631 & 59.891 & 133,052 & $-39,314$ & 5. 728 \\
\hline
\end{tabular}

$\triangle F^{\circ}$ and $\mathrm{K}$ are the free-energy change and equilibrium constant, respectively, for the reaction forming water from its elements in their stand. ard states at $T^{\circ} \mathrm{K}$

\section{Graphite}

The thermodynamic functions for graphite are given in tables 19 and 20 . They were obtained by tabular integration of the specific heat of graphite which has been measured $[41,42,43,44,45]$ within the range -244 to $1,200^{\circ} \mathrm{C}$. The values used for specific heats at the higher temperatures were also based in part on specific-heat measurements [46] on a carbon filament from $1,200^{\circ}$ to $2,100^{\circ} \mathrm{C}$.

TABLE 19.-Heat capacity at constant pressure, heat content, $H^{\circ}$, and $\left(H^{\circ}-E_{0}^{\circ}\right) / T$ for graphite

$$
\left[E_{0}^{\circ}=0\right]
$$

\begin{tabular}{|c|c|c|c|}
\hline$T$ & $\frac{H^{\circ}-E_{0}^{0}}{T}$ & $H^{\circ}$ & $C_{p}^{\circ}$ \\
\hline${ }^{\circ} \mathrm{K}$ & $\begin{array}{c}\text { cal deg-1 } \\
\text { mole } e^{-1}\end{array}$ & cal mole-1 & $\begin{array}{c}\text { cal deg-1 } \\
\text { mole } e^{-1}\end{array}$ \\
\hline 298.16 & 0.842 & 251 & 2. 055 \\
\hline 300.00 & .850 & 255 & 2. 071 \\
\hline 400 & 1. 258 & 503 & 2. 852 \\
\hline 500 & 1. 642 & 821 & 3. 488 \\
\hline 600 & 1. 993 & 1,196 & 3. 991 \\
\hline 700 & 2. 309 & 1,616 & 4. 391 \\
\hline 800 & 2. 590 & 2,072 & 4. 720 \\
\hline 900 & 2. 841 & 2,557 & 4. 972 \\
\hline 1,000 & 3. 064 & 3,064 & 5.159 \\
\hline 1,100 & 3. 262 & 3,588 & 5. 300 \\
\hline 1,200 & 3. 437 & 4,124 & 5.422 \\
\hline 1,300 & 3. 593 & 4,671 & 5. 520 \\
\hline 1,400 & 3. 734 & 5,227 & 5.609 \\
\hline 1,500 & 3. 862 & 5,793 & 5. 699 \\
\hline
\end{tabular}

TABLE 20.-Entropy, free energy, and the free-energy function for graphite

$\left[E_{0}^{*}=0\right]$

\begin{tabular}{|c|c|c|c|}
\hline$T$ & $-\left(\frac{F^{\circ}-E_{0}^{\circ}}{T}\right)$ & $S^{\circ}$ & $-F^{\circ}$ \\
\cline { 2 - 3 } & & & \\
\hline${ }^{\circ} K$ & $\begin{array}{c}\text { cal deg-1 } \\
\text { mole }\end{array}$ & $\begin{array}{c}\text { cal deg-1 } \\
\text { mole }{ }^{-1}\end{array}$ & cal mole-1 \\
298.16 & 0.525 & 1.367 & 157 \\
300.00 & 0.529 & 1.379 & 159 \\
400 & .830 & 2.088 & 332 \\
500 & 1.153 & 2.795 & 577 \\
600 & 1.484 & 3.477 & 890 \\
& & & \\
700 & 1.815 & 4.124 & 1,271 \\
800 & 2.142 & 4.732 & 1,714 \\
900 & 2.462 & 5.303 & 2,216 \\
1,000 & 2.774 & 5.838 & 2,774 \\
1,100 & 3.075 & 6.337 & 3,382 \\
& & & \\
1,200 & 3.367 & 6.804 & 4,040 \\
1,300 & 3.648 & 7.241 & 4,742 \\
1,400 & 3.919 & 7.653 & 5,487 \\
1,500 & 4.181 & 8.043 & 6,272 \\
& & & \\
\hline
\end{tabular}




\section{Hydrogen}

The thermodynamic functions for hydrogen given in tables 21 and 22 are from an unpublished

TABLE 21.- Heat capacity at constant pressure, heat content, and related quantities of hydrogen in the ideal gas state

$\left[E_{0}^{*}=0\right.$ ]

\begin{tabular}{|c|c|c|c|}
\hline$T$ & $\frac{H^{\circ}-E_{0}^{\circ}}{T}$ & $H^{\circ}$ & $C_{p}^{\circ}$ \\
\hline${ }^{\circ} \mathrm{K}$ & $\begin{array}{c}\text { cal deg }{ }^{-1} \\
\text { mole }^{-1}\end{array}$ & cal mole -1 & $\begin{array}{l}\text { cal deg - } \\
\text { mole }-1\end{array}$ \\
\hline 298.16 & 6.787 & 2023.8 & 6.891 \\
\hline 300.00 & 6.788 & 2036.4 & 6.894 \\
\hline 400 & 6. 827 & 2731.0 & 6.975 \\
\hline 500 & 6. 859 & 3429.5 & 6.993 \\
\hline 600 & 6. 883 & 4129.5 & 7. 009 \\
\hline 700 & 6. 902 & 4831.7 & 7.036 \\
\hline 800 & 6. 922 & 5537.3 & 7. 081 \\
\hline 900 & 6. 943 & 6248.3 & 7.142 \\
\hline 1,000 & 6. 966 & 6966.2 & 7. 219 \\
\hline 1,100 & 6. 993 & 7,692 & 7. 307 \\
\hline 1,200 & 7. 023 & 8,428 & 7. 406 \\
\hline 1,300 & 7. 057 & 9,174 & 7. 511 \\
\hline 1,400 & 7. 093 & 9,930 & 7.617 \\
\hline 1,500 & 7. 131 & 10,697 & 7. 720 \\
\hline
\end{tabular}

compilation of thermal properties of hydrogen [47].

TABLE 22.-Entropy ${ }^{a}$, free energy ${ }^{a}$, and related quantities of hydrogen in the ideal gas state at 1-atmosphere pressure

$\left[\boldsymbol{E}_{0}^{\mathfrak{0}}=0\right.$ ]

\begin{tabular}{|c|c|c|c|}
\hline$T$ & $-\left(\frac{F^{\circ}-E_{0}^{\circ}}{T}\right)$ & $S^{\circ}$ & $-F^{\circ}$ \\
\hline${ }^{\circ} K$ & $\begin{array}{c}\text { cal deg-1 } \\
\text { mole }^{-1}\end{array}$ & $\underset{\text { mole }^{-1}}{\text { cal deg }}$ & cal mole -1 \\
\hline 298.16 & 24.420 & 31.207 & 7,281 \\
\hline 300.00 & 24.462 & 31.250 & 7,339 \\
\hline 400 & 26.420 & 33. 247 & 10,568 \\
\hline 500 & 27. 947 & 34.806 & 13,974 \\
\hline 600 & 29.200 & 36.083 & 17,520 \\
\hline 700 & 30.263 & 37.165 & 21,184 \\
\hline 800 & 31.187 & 38.109 & 24,950 \\
\hline 900 & 32.003 & 38.946 & 28,803 \\
\hline 1,000 & 32.735 & 39. 701 & 32,735 \\
\hline 1,100 & 33.400 & 40. 393 & 36,740 \\
\hline 1,200 & 34,010 & 41.033 & 40,812 \\
\hline 1,300 & 34. 572 & 41. 629 & 44,944 \\
\hline 1,400 & 35.096 & 42.189 & 49,134 \\
\hline 1,500 & 35.588 & 42. 719 & 53,382 \\
\hline
\end{tabular}

- The nuclear spin entropy has been subtracted so that these values may be used directly in connection with chemical reactions.

\section{Oxygen}

Thermodynamic functions for oxygen are given in tables 23 and 24. These are based on the tables of Johnston and Walker [48] but have been adjusted to be consistent with a more recent value of Curry and Herzberg [49] for the vibrational frequency and with present generally accepted values of the fundamental physical constants. Curry and Herzberg represented the term values in $\mathrm{cm}^{-1}$ of the vibrational levels, with quantum number $v$, TABLE 23.-Heat capacity at constant pressure, heat content and related quantities of oxygen in the ideal gas state

$\left[E_{0}^{\circ}=0\right]$

\begin{tabular}{|c|c|c|c|}
\hline$T$ & $\frac{H^{\circ}-E_{0}^{\circ}}{T}$ & $H^{\circ}$ & $C_{\mathrm{p}}^{\circ}$ \\
\hline${ }^{\circ} K$ & $\begin{array}{c}\text { cal dég-1 } \\
\text { mole-1 }\end{array}$ & cal mole-1 & $\begin{array}{c}\text { cal } \text { deg-1 }^{-1} \\
\text { ole }^{-1}\end{array}$ \\
\hline 298.16 & 6. 941 & $-2,069.8$ & 7.019 \\
\hline 300.00 & 6.942 & $2,082.7$ & 7. 021 \\
\hline 400 & 6. 981 & $2,792.6$ & 7. 194 \\
\hline 500 & 7. 047 & $3,523.5$ & 7.430 \\
\hline 600 & 7. 131 & $4,278.6$ & 7. 669 \\
\hline 700 & 7. 223 & $5,056.4$ & 7. 882 \\
\hline 800 & 7. 317 & $5,853.8$ & 8. 062 \\
\hline 900 & 7. 409 & $6,667.7$ & 8.211 \\
\hline 1,000 & 7. 495 & $7,495.3$ & 8.335 \\
\hline 1,100 & 7. 576 & 8,334 & 8. 439 \\
\hline 1,200 & 7. 652 & 9,183 & 8. 528 \\
\hline 1,300 & 7. 723 & 10,040 & 8.606 \\
\hline 1,400 & 7. 789 & 10,904 & 8.675 \\
\hline 1,500 & 7. 849 & 11,774 & 8.739 \\
\hline
\end{tabular}

relative to the lowest vibrational level $(v=0)$ by the formula

$$
\left(1568.33 v-11.993 v^{2}+0.0517 v^{3}-0.00143 v^{4}\right) .
$$

The earlier, or 1933, tables of Johnston and Walker, from which the tables of this paper were obtained by adjustment, were based on the formula

$$
\left(1565.37 v-11.37 v^{2}\right) \text {. }
$$

TABLE 24.-Entropy, free energy, and related quantities of oxygen in the ideal gas state at 1-atmosphere pressure

$\left[E_{0}^{*}=0\right]$

\begin{tabular}{|c|c|c|c|}
\hline$T$ & $-\left(\frac{F^{\circ}-E_{0}^{\circ}}{T}\right)$ & $S^{\circ}$ & $-F^{\circ}$ \\
\hline${ }^{\circ} K$ & $\begin{array}{c}\text { cal deg-1 } \\
\text { mole }\end{array}$ & $\begin{array}{c}\text { cal deg-1 } \\
\text { mole }^{-1}\end{array}$ & cal mole-1 \\
298.16 & 42.067 & 49.008 & 12,543 \\
300.00 & 42.110 & 49.052 & 12,633 \\
400 & 44.112 & 51.093 & 17,645 \\
500 & 45.676 & 52.723 & 22,838 \\
600 & 46.968 & 54.099 & 28,181 \\
700 & 48.074 & 55.297 & 33,652 \\
800 & 49.045 & 56.362 & 39,236 \\
900 & 49.911 & 57.320 & 44,920 \\
1,000 & 50.697 & 58.192 & 50,697 \\
1,100 & 51.415 & 58.991 & 56,556 \\
1,200 & 52.078 & 59.730 & 62,494 \\
1,300 & 52.692 & 60.415 & 68,501 \\
1,400 & 53.267 & 61.056 & 74,574 \\
1,500 & 53.808 & 61.657 & 80,712 \\
& & & \\
\hline
\end{tabular}




\section{Heats of Formation at $0^{\circ} \mathrm{K}$}

The heats of formation at $0^{\circ} \mathrm{K}, E_{0}^{\circ}$, given in the tables of this paper were obtained from values of heats of formation at ordinary temperatures.

The calculation of $E_{0}^{\circ}$ for 1,3-butadiene is discussed in reference [4].

The heats of formation of the other substances at $298.16^{\circ} \mathrm{K}$ were based on values published or privately communicated by Rossini and his co- workers [50, 51, 52, 53].

Values of $E_{0}^{\circ}$ adopted for this paper should not be expected to agree exactly with previously published values of $E_{0}^{\circ}$, even though they are based on the same heats of formation at $298.16^{\circ} \mathrm{K}$, as the values of $E_{0}^{\circ}$ involve also values of $H^{\circ}-$ $E_{0}^{\circ}$, and the effects of rounding off values are also present.

\section{Equilibrium Constants}

The equilibrium constants of the reactions listed in section I are given in tables 25 to 29 as functions of the temperature from $298.16^{\circ}$ to $1,500^{\circ} \mathrm{K}$. These equilibrium constants were derived from data in tables 1 to 26 of this paper and tables for the $n$-butenes in reference [4].

The equilibrium constants $K_{p}$ are for pressures expressed in atmosperes, as the pressure chosen for the specification of the standard state is 1 atmosphere.

$$
\log _{10} K_{p}=-\Delta F^{\circ} /(2.3026 R T),
$$

where $\Delta F^{\circ}$ is the difference between the sums of the free energies of the products and of the reactants of the reaction to which $K_{p}$ applies, the free energies being those of pure substances in the ideal gaseous state at 1 atmosphere pressure and at temperature $T^{\circ} \mathrm{K}$. The values of $K_{p}$ in tables 25 to 29 are therefore calculated for reactions in the ideal gaseous state and differ from equilibrium constants for actual real gas conditions by amounts determined by the departure of real gas mixtures from ideal gas behavior.

Some reactions for which the equilibrium constants are given in tables 25 to 29 are discussed in the following paragraphs.

$$
\mathrm{C}_{6} \mathrm{H}_{6}+3 \mathrm{H}_{2} \rightleftharpoons \mathrm{C}_{6} \mathrm{H}_{12} \text { (cyclohexane) }
$$

The equilibrium constants for the hydrogenation of benzene to cyclohexane have been determined experimentally by Burrows and Lucarini [54] and by Zharkova and Frost [55]. Their experimentally determined constants are compared in table 30 with the calculated constants derived from the free energy data of this paper.

The equilibrium constant (table 25) varies rapidly with temperature. At ordinary temperatures, mixtures of benzene and hydrogen are very much less stable thermodynamically than cyclo-
TABLE 25.-Equilibrium constants $K_{p}$ (pressures in atmospheres) for the reactions:

(1) $\mathrm{C}_{6} \mathrm{H}_{6}(\mathrm{~g})+3 \mathrm{H}_{2} \rightleftharpoons \mathrm{C}_{6} \mathrm{H}_{12}$ (cyclohexane, g).

(2) $\mathrm{C}_{6} \mathrm{H}_{12}$ (cyclohexane, $\left.\mathrm{g}\right) \rightleftharpoons \mathrm{C}_{4} \mathrm{H}_{6}(1,3$-butadiene $)+\mathrm{C}_{2} \mathrm{H}_{4}+\mathrm{H}_{2}$.

(3) $\mathrm{C}_{6} \mathrm{H}_{12}$ (cyclohexane, $\left.\mathrm{g}\right) \rightleftharpoons \mathrm{C}_{4} \mathrm{H}_{6}(1,3$-butadiene $)+\mathrm{C}_{2} \mathrm{H}_{6}$.

\begin{tabular}{|c|c|c|c|}
\hline$T$ & $K_{p(1)}$ & $K_{p(2)}$ & $K_{p(3)}$ \\
\cline { 2 - 4 }${ }^{\circ} K$ & $a t m^{-3}$ & $a t m^{2}$ & atm \\
298.16 & $1.43 \times 10^{17}$ & $8.32 \times 10^{-34}$ & $4.15 \times 10^{-16}$ \\
300.00 & $8.53 \times 10^{10}$ & $1.69 \times 10^{-33}$ & $6.04 \times 10^{-10}$ \\
400 & $7.06 \times 10^{7}$ & $6.61 \times 10^{-21}$ & $2.34 \times 10^{-9}$ \\
500 & $1.85 \times 10^{2}$ & $2.94 \times 10^{-13}$ & $2.35 \times 10^{-5}$ \\
600 & $3.05 \times 10^{-2}$ & $4.12 \times 10^{-8}$ & $1.12 \times 10^{-2}$ \\
& & & \\
700 & $5.66 \times 10^{-5}$ & $1.95 \times 10^{-5}$ & 0.916 \\
800 & $4.94 \times 10^{-7}$ & 0.113 & 24.5 \\
900 & $1.23 \times 10^{-3}$ & 15.7 & $3.10 \times 10^{2}$ \\
1,000 & $6.49 \times 10^{-10}$ & $8.03 \times 10^{2}$ & $2.30 \times 10^{8}$ \\
1,100 & $5.89 \times 10^{-11}$ & $1.97 \times 10^{4}$ & $1.16 \times 10^{4}$ \\
& & & \\
1,200 & $8.09 \times 10^{-12}$ & $2.79 \times 10^{5}$ & $4.40 \times 10^{4}$ \\
1,300 & $1.53 \times 10^{-12}$ & $2.56 \times 10^{6}$ & $1.33 \times 10^{5}$ \\
1,400 & $3.75 \times 10^{-13}$ & $1.69 \times 10^{7}$ & $3.40 \times 10^{5}$ \\
1,500 & $1.11 \times 10^{-13}$ & $8.61 \times 10^{7}$ & $7.55 \times 10^{5}$ \\
& & & \\
\hline
\end{tabular}

hexane, whereas at high temperatures of the order of $1,000^{\circ} \mathrm{K}$, cyclohexane is very much less stable. Because of the rapid variation of $K_{p}$ with temperature, experimental determinations of the equilibrium constant have been limited practically to a fifty degree range of temperatures from about $500^{\circ}$ to $550^{\circ} \mathrm{K}$. Considering this rapid variation, the agreement of the experimental and calculated equilibrium constants in table 30 is considered satisfactory.

$\mathrm{C}_{6} \mathrm{H}_{12}$ (cyclohexane) $\rightleftharpoons$

$\mathrm{C}_{4} \mathrm{H}_{6}$ (1,3-butadiene) $+\mathrm{C}_{2} \mathrm{H}_{4}+\mathrm{H}_{2}$

In the thermal cracking of cyclohexane for commercial production of butadiene, cyclohexane is passed through a tube into which superheated steam at a high temperature (about $1,300^{\circ} \mathrm{K}$ ) is injected to raise the temperature of the cyclo- 
TABLE 26.-Equilibrium constants $K_{p}$ (pressures in atmosspheres) for the reactions:

(1) $\mathrm{C}_{6} \mathrm{H}_{12}$ (cyclohexane, $\mathrm{g}$ ) $\rightleftharpoons \mathrm{C}_{4} \mathrm{H}_{6}\left(1,3\right.$-butadiene) $+\mathrm{C}_{2} \mathrm{H}_{2}+$ $2 \mathrm{H}_{2}$.

(2) $\mathrm{C}_{6} \mathrm{H}_{12}$ (cyclohexane, $\left.\mathrm{g}\right) \rightleftharpoons \frac{3}{2} \mathrm{C}_{4} \mathrm{H}_{6}(1,3$-butadiene $)+\frac{3}{2} \mathrm{H}_{2}$

(3) $\mathrm{C}_{6} \mathrm{H}_{12}$ (cyclohexane, $\mathrm{g}$ ) $\rightleftharpoons 3 \mathrm{C}_{2} \mathrm{H}_{4}$.

(4) $2 \mathrm{C}_{2} \mathrm{H}_{4} \rightleftharpoons \mathrm{C}_{4} \mathrm{H}_{6}(1,3$-butadiene $)+\mathrm{H}_{2}$.

\begin{tabular}{|c|c|c|c|c|}
\hline$T$ & $K_{p(1)}$ & $K_{p(2)}$ & $K_{p(3)}$ & $K_{p(4)}$ \\
\hline${ }^{\circ} K$ & at $m^{3}$ & atm ${ }^{2}$ & atm ${ }^{2}$ & at $m^{0}$ \\
\hline 298.16 & 1. $61 \times 10^{-58}$ & 3. $24 \times 10^{-35}$ & 5. $50 \times 10^{-31}$ & 1. $51 \times 10^{-3}$ \\
\hline 300.00 & 5. $20 \times 10^{-58}$ & $6.64 \times 10^{-36}$ & 1. $10 \times 10^{-30}$ & 1. $54 \times 10^{-3}$ \\
\hline 400 & $8.83 \times 10^{-38}$ & 3. $93 \times 10^{-22}$ & 1. $88 \times 10^{-18}$ & $3.52 \times 10^{-3}$ \\
\hline 500 & 1. $78 \times 10^{-26}$ & $2.40 \times 10^{-14}$ & 4. $40 \times 10^{-11}$ & $6.68 \times 10^{-3}$ \\
\hline 600 & 2. $95 \times 10^{-17}$ & 4. $26 \times 10^{-9}$ & $3.86 \times 10^{-6}$ & 1. $07 \times 10^{-2}$ \\
\hline 700 & 2. $99 \times 10^{-11}$ & 2. $54 \times 10^{-6}$ & $1.14 \times 10^{-2}$ & 1. $70 \times 10^{-2}$ \\
\hline 800 & $8.83 \times 10^{-7}$ & 1. $75 \times 10^{-2}$ & 4. 67 & $2.42 \times 10^{-2}$ \\
\hline 900 & 2. $66 \times 10^{-3}$ & 2.84 & 4. $83 \times 10^{2}$ & 3. $26 \times 10^{-2}$ \\
\hline 1,000 & 1. 59 & 1. $64 \times 10^{2}$ & 1. $91 \times 10^{4}$ & 4. $20 \times 10^{-2}$ \\
\hline 1,100 & 2. $94 \times 10^{2}$ & 4. $52 \times 10^{3}$ & 3. $76 \times 10^{8}$ & 5. $25 \times 10^{-2}$ \\
\hline 1,200 & 2. $23 \times 10^{4}$ & 7. $01 \times 10^{4}$ & 4. $40 \times 10^{6}$ & 6. $34 \times 10^{-2}$ \\
\hline 1,300 & 8. $53 \times 10^{6}$ & $7.05 \times 10^{5}$ & $3.40 \times 10^{7}$ & 7. $53 \times 10^{-2}$ \\
\hline 1,400 & 1. $90 \times 10^{7}$ & 5. $01 \times 10^{0}$ & $1.94 \times 10^{8}$ & 8. $73 \times 10^{-2}$ \\
\hline 1,500 & 2. $76 \times 10^{3}$ & 2. $72 \times 10^{7}$ & 8. $67 \times 10^{8}$ & 9. $93 \times 10^{-2}$ \\
\hline
\end{tabular}

TABLE 27.-Equilibrium constant $K_{p}\left(a t m^{-1}\right)$, for the reaction $2 \mathrm{C}_{2} \mathrm{H}_{4} \rightleftharpoons n-\mathrm{C}_{4} \mathrm{H}_{8}$ (1-butene, cis and trans-2butene and the equilibrium mixture of the n-butenes)

\begin{tabular}{|c|c|c|c|c|}
\hline$T$ & $\begin{array}{c}K_{p}\left(\mathrm{~atm}^{-1}\right) \\
\text { 1-butene }\end{array}$ & $\begin{array}{l}K_{p}\left(\mathrm{~atm}^{-1}\right) \\
\text { cis-2-butene }\end{array}$ & $\begin{array}{c}K_{p}(\mathrm{~atm}-1) \\
\text { trans-2-butene }\end{array}$ & $\begin{array}{c}\left.K_{p}\left(a^{-1}\right)^{-1}\right) \\
\text { equilibrium } \\
\text { mixture } \\
n \text {-butenes }\end{array}$ \\
\hline${ }^{\circ} K$ & & & & \\
\hline 298.16 & 1. $38 \times 10^{11}$ & 1. $27 \times 10^{12}$ & 4. $67 \times 10^{12}$ & $6.08 \times 10^{12}$ \\
\hline 300.00 & 1. $07 \times 10^{11}$ & $9.70 \times 10^{11}$ & 3. $52 \times 10^{12}$ & 4. $59 \times 10^{12}$ \\
\hline 400 & $3.40 \times 10^{6}$ & 1. $48 \times 10^{7}$ & $3.60 \times 10^{7}$ & $5.42 \times 10^{7}$ \\
\hline 500 & $6.84 \times 10^{3}$ & 1. $85 \times 10^{4}$ & $3.63 \times 10^{4}$ & $6.16 \times 10^{4}$ \\
\hline 600 & 1. $06 \times 10^{2}$ & 2. $01 \times 10^{2}$ & 3. $51 \times 10^{2}$ & 6. $58 \times 10^{2}$ \\
\hline 700 & 5.86 & 8.57 & 1. $39 \times 10$ & 2. $83 \times 10$ \\
\hline 800 & 6. $55 \times 10^{-1}$ & $7.80 \times 10^{-1}$ & 1. 21 & 2.64 \\
\hline 900 & 1. $20 \times 10^{-1}$ & 1. $21 \times 10^{-1}$ & $1.81 \times 10^{-1}$ & 4. $22 \times 10^{-1}$ \\
\hline 1,000 & $3.11 \times 10^{-2}$ & 2. $74 \times 10^{-2}$ & 4. $00 \times 10^{-2}$ & $9.85 \times 10^{-2}$ \\
\hline 1,100 & $1.04 \times 10^{-2}$ & $8.20 \times 10^{-3}$ & $1.18 \times 10^{-2}$ & $3.04 \times 10^{-2}$ \\
\hline 1,200 & 4. $17 \times 10^{-3}$ & 3. $01 \times 10^{-3}$ & 4. $26 \times 10^{-3}$ & 1. $14 \times 10^{-2}$ \\
\hline 1,300 & 1. $95 \times 10^{-3}$ & 1. $30 \times 10^{-3}$ & $1.82 \times 10^{-3}$ & 5. $07 \times 10^{-3}$ \\
\hline 1,400 & 1. $02 \times 10^{-3}$ & $6.32 \times 10^{-4}$ & $8.85 \times 10^{-4}$ & 2. $54 \times 10^{-3}$ \\
\hline 1,500 & 5. $82 \times 10^{-4}$ & $3.40 \times 10^{-4}$ & 4. $69 \times 10^{-4}$ & 1. $39 \times 10^{-3}$ \\
\hline
\end{tabular}

TABLE 28.-Equilibrium constants $K_{\mathrm{D}}$ (pressures in atmospheres) for the reactions:

(1) $\mathrm{C}_{2} \mathrm{H}_{6} \rightleftharpoons \mathrm{C}_{2} \mathrm{H}_{4}+\mathrm{H}_{2}$.

(2) $2 \mathrm{C}_{2} \mathrm{H}_{5} \mathrm{OH} \rightleftharpoons \mathrm{C}_{4} \mathrm{H}_{6}(1,3$-butadiene $)+2 \mathrm{H}_{2} \mathrm{O}+\mathrm{H}_{2}$.

(3) $\mathrm{C}_{2} \mathrm{H}_{4}+\mathrm{H}_{2} \mathrm{O} \rightleftharpoons \mathrm{C}_{2} \mathrm{H}_{5} \mathrm{OH}$.

(4) $\mathrm{C}_{2} \mathrm{H}_{4}+\mathrm{C}_{2} \mathrm{H}_{2} \rightleftharpoons \mathrm{C}_{4} \mathrm{H}_{6}$ (1,3-butadiene).

\begin{tabular}{|c|c|c|c|c|}
\hline$T$ & $K_{p(1)}$ & $K_{p(2)}$ & $K_{p(3)}$ & $K_{p(4)}$ \\
\hline${ }^{\circ} \mathrm{K}$ & atm & $a t m^{2}$ & at $m^{-1}$ & $a^{-1}$ \\
\hline 298.16 & $2.00 \times 10^{-18}$ & $5.43 \times 10^{-8}$ & 1. $66 \times 10$ & 7. $78 \times 10^{21}$ \\
\hline 300.00 & 2. $80 \times 10^{-18}$ & $6.97 \times 10^{-6}$ & 1. $49 \times 10$ & $5.13 \times 10^{21}$ \\
\hline 400 & 2. $82 \times 10^{-12}$ & 1. $57 \times 10^{-1}$ & 1. $49 \times 10^{-1}$ & 2. $64 \times 10^{14}$ \\
\hline 500 & 1. $25 \times 10^{-8}$ & 7. $46 \times 10$ & $9.47 \times 10^{-3}$ & 1. $10 \times 10^{10}$ \\
\hline 600 & 3. $68 \times 10^{-6}$ & $4.90 \times 10^{3}$ & 1. $51 \times 10^{-3}$ & 1. $30 \times 10^{7}$ \\
\hline 700 & 2. $12 \times 10^{-4}$ & 1. $00 \times 10^{5}$ & 4. $13 \times 10^{4}$ & 1. $10 \times 10^{5}$ \\
\hline 800 & 4. $60 \times 10^{-3}$ & 9. $66 \times 10^{5}$ & 1. $58 \times 10^{-4}$ & $3.08 \times 10^{3}$ \\
\hline 900 & 5. $08 \times 10^{-2}$ & 5. $66 \times 10^{6}$ & 7. $59 \times 10^{-5}$ & 1. $93 \times 10^{2}$ \\
\hline 1,000 & 0.349 & 2. $31 \times 10^{7}$ & 4. $27 \times 10^{-5}$ & 21.2 \\
\hline 1,100 & 1. 70 & 7. $28 \times 10^{7}$ & 2. $68 \times 10^{-5}$ & 3.53 \\
\hline 1,200 & 6.34 & 1. $85 \times 10^{8}$ & 1. $85 \times 10^{-5}$ & 0. 792 \\
\hline 1,300 & 19.2 & 4. $08 \times 10^{8}$ & 1. $36 \times 10^{-5}$ & 0.226 \\
\hline 1,400 & 49.9 & 7. $92 \times 10^{8}$ & $1.04 \times 10^{-5}$ & 7. $78 \times 10^{-2}$ \\
\hline 1,500 & 114.0 & 1. $40 \times 10^{9}$ & $0.84 \times 10^{-5}$ & 3. $10 \times 10^{-2}$ \\
\hline
\end{tabular}

TABLE 29.-Equilibrium constants $K_{p}$ (pressures in atmospheres) for the reactions:

(1) $\mathrm{C}_{2} \mathrm{H}_{4} \rightleftharpoons \mathrm{C}_{2} \mathrm{H}_{2}+\mathrm{H}_{2}$.

(2) $\mathrm{C}_{2} \mathrm{H}_{6} \rightleftharpoons \mathrm{C}_{2} \mathrm{H}_{2}+2 \mathrm{H}_{2}$.

(3) $\mathrm{C}_{2} \mathrm{H}_{4}+\mathrm{C}_{4} \mathrm{H}_{6}(1,3$-butadiene $) \rightleftharpoons \mathrm{C}_{6} \mathrm{H}_{6}(g)+2 \mathrm{H}_{2}$.

(4) $2 \mathrm{C}_{4} \mathrm{H}_{6}\left(1,3\right.$-butadiene) $\rightleftharpoons \mathrm{C}_{6} \mathrm{H}_{6}(g)+\mathrm{C}_{2} \mathrm{H}_{4}+\mathrm{H}_{2}$.

\begin{tabular}{|c|c|c|c|c|}
\hline$T$ & $K_{p(1)}$ & $K_{p(2)}$ & $K_{p(3)}$ & $K_{p(4)}$ \\
\hline${ }^{\circ} K$ & atm & $a t m^{2}$ & atm & atm \\
\hline 298.16 & 1. $94 \times 10^{-25}$ & 3. $88 \times 10^{-43}$ & $8.41 \times 10^{15}$ & 5. $57 \times 10^{18}$ \\
\hline 300.00 & 3. $00 \times 10^{-25}$ & $8.41 \times 10^{-43}$ & 6. $92 \times 10^{15}$ & 4. $49 \times 10^{18}$ \\
\hline 400 & 1. $34 \times 10^{-17}$ & 3. $77 \times 10^{-29}$ & $2.14 \times 10^{12}$ & $6.08 \times 10^{14}$ \\
\hline 500 & $6.08 \times 10^{-13}$ & 7. $60 \times 10^{-21}$ & $1.84 \times 10^{10}$ & 2. $75 \times 10^{12}$ \\
\hline 600 & 8. $22 \times 10^{-10}$ & 3. $03 \times 10^{-15}$ & $7.96 \times 10^{8}$ & $7.46 \times 10^{10}$ \\
\hline 700 & 1. $54 \times 10^{-7}$ & 3. $27 \times 10^{-11}$ & $9.08 \times 10^{7}$ & 5. $35 \times 10^{9}$ \\
\hline 800 & $7.84 \times 10^{-6}$ & 3. $61 \times 10^{-8}$ & 1. $79 \times 10^{7}$ & $7.43 \times 10^{8}$ \\
\hline 900 & 1. $69 \times 10^{-4}$ & 8. $59 \times 10^{-6}$ & $5.15 \times 10^{6}$ & $1.58 \times 10^{8}$ \\
\hline 1,000 & $1.98 \times 10^{-3}$ & 6. $92 \times 10^{-4}$ & 1. $92 \times 10^{6}$ & 4. $57 \times 10^{7}$ \\
\hline 1,100 & $1.49 \times 10^{-2}$ & 2. $53 \times 10^{-2}$ & $8.61 \times 10^{5}$ & 1. $64 \times 10^{7}$ \\
\hline 1,200 & $8.00 \times 10^{-2}$ & 0.507 & 4. $44 \times 10^{5}$ & $7.00 \times 10^{6}$ \\
\hline 1,300 & 0.333 & 6. 40 & 2. $54 \times 10^{5}$ & $3.37 \times 10^{6}$ \\
\hline 1,400 & 1.12 & 56.0 & 1. $57 \times 10^{5}$ & $1.80 \times 10^{6}$ \\
\hline 1,500 & 3. 21 & 290.0 & $1.04 \times 10^{5}$ & $1.05 \times 10^{8}$ \\
\hline
\end{tabular}


TABLE 30.-A comparison of calculated and experimental values for the equilibrium constant $K_{p}$ for the reaction:

$$
\mathrm{C}_{6} \mathrm{H}_{6}+3 \mathrm{H}_{2} \rightleftharpoons \mathrm{C}_{6} \mathrm{H}_{12}
$$

\begin{tabular}{|c|c|c|c|}
\hline$T$ & $\begin{array}{c}K_{p} \text { (calcu- } \\
\text { lated) }\end{array}$ & $\begin{array}{c}K_{p} \text { (experi- } \\
\text { mental) }\end{array}$ & Observers \\
\hline${ }^{\circ} \mathrm{K}$ & atm-3 & atm $^{-3}$ & \\
\hline 503.1 & 134.0 & 135.0 & (55) \\
\hline 503.3 & 132.0 & 104.0 & (55) \\
\hline 503. 5 & 129.0 & 77.0 & (55) \\
\hline 522.6 & 19.5 & 11.0 & (55) \\
\hline 522.6 & 19.5 & 10.7 & (55) \\
\hline 523.1 & 18.6 & 12.6 & (55) \\
\hline 523.4 & 18.1 & 11.7 & (55) \\
\hline 523.4 & 18.1 & 16.0 & (55) \\
\hline 523.6 & 17.8 & 15.4 & (55) \\
\hline 540.0 & 3. 92 & 5. 10 & (54) \\
\hline 540.0 & 3. 92 & 5.49 & (54) \\
\hline 540.0 & 3. 92 & 5. 40 & (54) \\
\hline 540.0 & 3. 92 & 5. 51 & (54) \\
\hline 548.1 & 1. 91 & 1. 61 & (55) \\
\hline 548.1 & 1. 91 & 1. 56 & (55) \\
\hline 548.6 & 1.84 & 1. 18 & (55) \\
\hline 549.6 & 1. 68 & 1. 11 & (55) \\
\hline 553.2 & 1. 23 & 1. 52 & (54) \\
\hline 553. 2 & 1. 23 & 1.60 & (54) \\
\hline 553.2 & 1. 23 & 1. 63 & (54) \\
\hline
\end{tabular}

- (54) G. H. Burrows and C. Lucarini, (55) Z. R. Zharkova and A. V. Frost.

hexane from about $900^{\circ}$ to $1,000^{\circ} \mathrm{K}$. Under these conditions it is probable that the above reaction is one of the principal primary reactions taking place.

As will be seen from table 26 the square of the concentration of $\mathrm{C}_{2} \mathrm{H}_{4}$ in thermodynamic equilibrium with butadiene at $1,000^{\circ} \mathrm{K}$ is about 24 times the product of the concentrations of $\mathrm{C}_{4} \mathrm{H}_{6}$ and $\mathrm{H}_{2}$. For the same concentration of $\mathrm{H}_{2}$ and $\mathrm{C}_{4} \mathrm{H}_{6}$ this means that the concentration of $\mathrm{C}_{2} \mathrm{H}_{4}$ is about 5 times that of butadiene. Schneider and Frolich [56] have shown that butadiene and hydrogen are the principal initial products resulting from the pyrolysis of etheylene, from which it would be inferred that the rate of cracking of butadiene to form ethylene must be appreciable. Hence in the production of butadiene from cyclohexane, the temperature of a cracked cyclohexane product high in butadiene should be lowered in a reasonably short time. As in the cracking reaction of cyclohexane, butadiene, and ethylene are formed in equal concentrations the establishment of thermodynamic equilibrium between $\mathrm{C}_{2} \mathrm{H}_{4}, \mathrm{C}_{4} \mathrm{H}_{6}$, and $\mathrm{H}_{2}$ decreases the yield of butadiene.
$\mathrm{C}_{6} \mathrm{H}_{12}$ (cyclohexane) $\rightleftharpoons \mathrm{C}_{4} \mathrm{H}_{6}(1,3$-butadiene $)+\mathrm{C}_{2} \mathrm{H}_{6}$

Ethane is not formed to any appreciable extent as a primary product in the thermal cracking of cyclohexane. The equilibrium indicated by the equation heading this subsection is probably the result of the two reactions:

$$
\begin{gathered}
\mathrm{C}_{6} \mathrm{H}_{12} \rightleftharpoons \mathrm{C}_{4} \mathrm{H}_{6}+\mathrm{C}_{2} \mathrm{H}_{4}+\mathrm{H}_{2} \\
\mathrm{C}_{2} \mathrm{H}_{4}+\mathrm{H}_{2} \rightleftharpoons \mathrm{C}_{2} \mathrm{H}_{6}
\end{gathered}
$$

With increase of pressure on the gaseous system the concentration of ethane will increase relative to the concentration of ethylene in accordance with the law of mass action.

$$
2 \mathrm{C}_{2} \mathrm{H}_{4} \rightleftharpoons \mathrm{C}_{4} \mathrm{H}_{6}+\mathrm{H}_{2}
$$

In the pyrolysis of ethylene at $725^{\circ} \mathrm{C}\left(1,000^{\circ}\right.$ K) Schneider and Frolich [56] found that 72 percent of the product initially formed is $\mathrm{C}_{4} \mathrm{H}_{6}$ and $\mathrm{H}_{2}$. According to these authors the rate of the reaction is first order or less, indicating an intermediate reaction, possibly that of formation of an excited ethylene molecule or a free vinyl radical.

$$
2 \mathrm{C}_{2} \mathrm{H}_{4} \rightleftharpoons n-\mathrm{C}_{4} \mathrm{H}_{8}
$$

Schneider and Frolich [61] observed that butenes are initial products in the pyrolysis of $\mathrm{C}_{2} \mathrm{H}_{4}$. In table 27 are given the equilibrium constants for the separate reactions forming 1-butene, cis-2butene, trans-2-butene and an equilibrium mixture of $n$-butenes. The thermodynamic data on the butenes used in the calculation of these equilibrium constants were taken from reference [4].

$$
\mathrm{C}_{2} \mathrm{H}_{6} \rightleftharpoons \mathrm{C}_{2} \mathrm{H}_{4}+\mathrm{H}_{2}
$$

Experimental determinations of the equilibrium constant $K_{p}$ for this reaction have been made by Kistiakowsky [57], Frey and Huppke [58], Videnski and Vinikova [59], Travers and Pearce [60], Pease and Durgan [61], and Travers and Hockin [62]. In table 31 their results are compared with calculated values interpolated from table 28 .

$$
\begin{aligned}
& 2 \mathrm{C}_{2} \mathrm{H}_{5} \mathrm{OH}(\mathrm{g}) \rightleftharpoons \mathrm{C}_{4} \mathrm{H}_{6} \text { (1,3-butadiene) }+ \\
& 2 \mathrm{H}_{2} \mathrm{O}(\mathrm{g})+\mathrm{H}_{2}
\end{aligned}
$$

In the Lebeder process for making butadiene, ethyl alcohol is passed over a mixed dehydrogenation-dehydration catalyst at a temperature of about $700^{\circ} \mathrm{K}$. The over-all reaction of the process is as written above. It is likely, however, that intermediate reactions are involved. 
TABLE 31.-A comparison of calculated and experimental values for the equilibrium constant $K_{p}$ for the reaction:

$$
\mathrm{C}_{2} \mathrm{H}_{6} \rightleftharpoons \mathrm{C}_{2} \mathrm{H}_{4}+\mathrm{H}_{2}
$$

\begin{tabular}{|c|c|c|c|}
\hline$K$ & $\stackrel{K_{p}}{\text { (calculated) }}$ & $\begin{array}{c}K_{p} \\
\text { (experi- } \\
\text { mental) }\end{array}$ & Observersa \\
\hline${ }^{\circ} K$ & $a t m$ & atm & \\
\hline 653 & 3. $68 \times 10^{-5}$ & $4.04 \times 10^{-5}$ & (57) \\
\hline 673 & $7.98 \times 10^{-5}$ & 8. $2 \times 10^{-5}$ & (58) \\
\hline 723 & $4.63 \times 10^{-4}$ & $\left\{\begin{array}{l}5.16 \times 10^{-4} \\
5.6 \times 10^{-4}\end{array}\right.$ & $\begin{array}{l}(57) \\
(58)\end{array}$ \\
\hline 773 & $2.16 \times 10^{-3}$ & $\left\{\begin{array}{l}3.2 \times 10^{-3} \\
2.4 \times 10^{-3}\end{array}\right.$ & $\begin{array}{l}(59) \\
(58)\end{array}$ \\
\hline 823 & $8.41 \times 10^{-3}$ & $7.4 \times 10^{-3}$ & (60) \\
\hline 843 & 0.0139 & 0.0153 & (60) \\
\hline 863 & .0223 & $\left\{\begin{array}{l}.0244 \\
.0245\end{array}\right.$ & $\begin{array}{l}(60) \\
(61)\end{array}$ \\
\hline 873 & .0281 & .031 & (61) \\
\hline 883 & .0351 & $\left\{\begin{array}{l}.0359 \\
.033\end{array}\right.$ & $\begin{array}{l}(60) \\
(62)\end{array}$ \\
\hline 893 & .0438 & .0446 & (60) \\
\hline 903 & .0542 & .054 & $(60)$ \\
\hline 923 & .0822 & $\left\{\begin{array}{l}.082 \\
.078\end{array}\right.$ & $\begin{array}{l}(61) \\
(60)\end{array}$ \\
\hline 973 & .216 & .20 & (61) \\
\hline
\end{tabular}

- (57) G. B. Kistiakowsky, (58) F. E. Frey and W. F. Huppke, recalculated, G. B. Kistiakowsky, H. Romeyn, J. R. Ruhoff, H. A. Smith, and W. E. Vaughan, (59) A. A. Videnski and S. G. Vinikova, (60) M. W. Travers and T. J. P. Pearce, (61) R. N. Pease and E. S. Durgan, (62) M. W. Travers and L. E. Hockin.

$$
\mathrm{C}_{2} \mathrm{H}_{4}+\mathrm{H}_{2} \mathrm{O} \rightleftharpoons \mathrm{C}_{2} \mathrm{H}_{5} \mathrm{OH}
$$

Experimental determinations of $K_{p}$ for this reaction have been made by Stanley, Youell and Dymock [63], Appleby, Glass, and Horsley [64], and Bliss and Dodge [65]. The experimental values of $K_{p}$ are compared with calculated values in table 32 .

$$
\mathrm{C}_{2} \mathrm{H}_{4}+\mathrm{C}_{4} \mathrm{H}_{6}(1,3 \text {-butadiene }) \rightleftharpoons \mathrm{C}_{6} \mathrm{H}_{6}(\mathrm{~g})+2 \mathrm{H}_{2}
$$

Schneider and Frolich [56] found that benzene was the most abundant single initial product resulting from the pyrolysis of a mixture of ethylene (90 percent) and butadiene (10 percent) at $1,000^{\circ} \mathrm{K}$ and one-fifth of an atmosphere. It is probable that there is an intermediate metastable complex formed by $\mathrm{C}_{2} \mathrm{H}_{4}$ and $\mathrm{C}_{4} \mathrm{H}_{6}$, possibly the triolefin $\mathrm{C}_{6} \mathrm{H}_{8}$, which breaks down, giving $\mathrm{C}_{6} \mathrm{H}_{6}$.

$$
2 \mathrm{C}_{4} \mathrm{H}_{6}(1,3 \text {-butadiene }) \rightleftharpoons \mathrm{C}_{6} \mathrm{H}_{6}(\mathrm{~g})+\mathrm{C}_{2} \mathrm{H}_{4}+\mathrm{H}_{2}
$$

Schneider and Frolich [56] suggest that benzene may be formed as a result of a coalescence of two

\begin{tabular}{|c|c|c|c|}
\hline$T$ & $\begin{array}{c}K_{p} \text { (calcu- } \\
\text { lated) }\end{array}$ & $\begin{array}{c}K_{p} \text { (experi- } \\
\text { mental) }\end{array}$ & Observers a \\
\hline${ }^{\circ} \mathrm{K}$ & $a t m^{-1}$ & $a \mathrm{t} m^{-1}$ & \\
\hline 418 & 8. $28 \times 10^{-2}$ & $6.8 \times 10^{-2}$ & (68) \\
\hline 448 & $3.42 \times 10^{-2}$ & $\begin{array}{l}\text { 3. } 6 \times 10^{-2} \\
\text { 2. } 93 \times 10^{-2}\end{array}$ & $\begin{array}{l}(68) \\
(69)\end{array}$ \\
\hline 473 & 1. $78 \times 10^{-2}$ & $\begin{array}{l}1.65 \times 10^{-2} \\
1.72 \times 10^{-2}\end{array}$ & $\begin{array}{l}(68) \\
(69)\end{array}$ \\
\hline 498 & $0.989 \times 10^{-2}$ & $\begin{array}{l}\text { 1. } 07 \times 10^{-2} \\
0.984 \times 10^{-2}\end{array}$ & $\begin{array}{l}(68) \\
(69)\end{array}$ \\
\hline 523 & 5. $83 \times 10^{-3}$ & $\left\{\begin{array}{l}6.7 \times 10^{-3} \\
6.28 \times 10^{-3}\end{array}\right.$ & $\begin{array}{l}\text { (68) } \\
(69)\end{array}$ \\
\hline 548 & 3. $61 \times 10^{-3}$ & 3. $83 \times 10^{-3}$ & (69) \\
\hline 593 & 1. $68 \times 10^{-3}$ & 1. $87 \times 10^{-3}$ & (70) \\
\hline 623 & 1. $07 \times 10^{-3}$ & 1. $49 \times 10^{-3}$ & (70) \\
\hline 651 & $.736 \times 10^{-3}$ & 1. $26 \times 10^{-3}$ & (70) \\
\hline
\end{tabular}
butadiene molecules.

TABLE 32.-A comparison of calculated and experimental values for the equilibrium constant $K_{p}$ of the reaction:

s (63) H. M. Stanley, J. E. Youell, J. B. Dymock, (64) M. P. Applebey, J. V. S. Glass, G. F. Horsley, (65) R. H. Bliss, B. F. Dodge.

$$
\mathrm{C}_{2} \mathrm{H}_{4}+\mathrm{C}_{2} \mathrm{H}_{2} \rightleftharpoons \mathrm{C}_{4} \mathrm{H}_{8} \text { (1, 3-butadiene) }
$$

The reaction forming butadiene from ethylene and acetylene in equimolar proportion was reported in 1866 by Berthelot [66] and has been studied recently by Naragon, Burk, and Lankelma [67], who conclude that acetylene in the absence of catalysts reacts more readily with ethylene than ethylene does with itself. As acetylene is so reactive, other reactions also occur, leading to products of higher molecular weight. Considering that the equilibrium constant for the formation of butadiene from ethylene and acetylene is very favorable at low and moderate temperatures, a catalyst specific for this reaction is desirable [68].

\section{Comments on Cracking Reactions}

The law of mass action and tables of equilibrium constants for different temperatures are helpful in the analysis of data on the products of cracking and condensation reactions of hydrocarbons. Thus tables of equilibrium constants show how, with increase of temperature, the equilibrium concentrations of unsaturated hydrocarbons increase with respect to the saturated hydrocarbons. The law of mass action determines the expected rate of increase in the relative equilibrium concentration of saturated hydrocarbons with increase of pressure. Besides depending upon temperature and pressure, the relative equilibrium concentrations of saturated and unsaturated hydrocarbons formed 
by cracking and condensation reactions are dependent upon the carbon to hydrogen ratio of the starting material, assuming no deposition of free carbon. The higher the carbon to hydrogen ratio, the greater the relative equilibrium concentration of the unsaturated hydrocarbons.

Two investigations of the products of the thermal cracking of hexane, one at high [69] and the other at low pressure [70], illustrate in a striking manner the influence of changes of pressure upon equilibrium concentrations. Thus at a pressure of 1,000 atmospheres and at temperatures of $783^{\circ} \mathrm{K}$, there was no measurable concentration of hydrogen or any unsaturated hydrocarbon, whereas at a pressure of 0.18 atmosphere and $698^{\circ} \mathrm{K}$ the concentration of the unsaturated hydrocarbons exceeded that of the saturated compounds. In low pressure cracking reactions, equilibrium is approached from the side of low concentration of unsaturates, and in high pressure cracking from the side of high concentration of unsaturates.

The establishment of approximate equilibrium concentrations of hydrocarbons at temperatures of $700^{\circ}$ to $800^{\circ} \mathrm{K}$ in the absence of catalysts requires times of the order of several hours. Thus in the products of a cracking process at high pressures [69] involving several reactions, one finds that the ratio $P\left[\mathrm{C}_{2} \mathrm{H}_{4}\right] \cdot P\left[\mathrm{H}_{2}\right] / P\left[\mathrm{C}_{2} \mathrm{H}_{6}\right]$ changes from about 0.75 atmosphere to about 0.03 atmosphere during a period of about 2 hours at temperatures of $730^{\circ} \mathrm{K}$. The equilibrium value is about $10^{-3}$ atmosphere. When several reactions occur in succession, the slowest reaction controls the approach to final equilibrium. For the most rapid reaction the apparent equilibrium constant as calculated from experimental compositions approaches the theoretical value relatively soon even though general equilibrium is not yet attained, so that the individual compositions continue to change. In cracking gas oil at $1,223^{\circ} \mathrm{K}$ [71] and 0.23 atmosphere, the proportions of $\mathrm{C}_{4} \mathrm{H}_{6}, \mathrm{H}_{2}$, and $\mathrm{C}_{2} \mathrm{H}_{4}$ after a "contact time" of 0.05 second are fairly consistent with the equilibrium constant for the reaction $2 \mathrm{C}_{2} \mathrm{H}_{4} \leftrightarrows$ $\mathrm{C}_{4} \mathrm{H}_{6}+\mathrm{H}_{2}$ as given in table 27 , whereas the proportions of butanes, butenes, butadiene, ethylene, ethane, and hydrogen were not yet in approximate agreement with equilibrium constants for simple dehydrogenation reactions. On the other hand, the compositions obtained in the cracking of isobutane [72], probably at about atmospheric pressure, near $873^{\circ} \mathrm{K}$ and $923^{\circ} \mathrm{K}$ indicate values of $P\left[\mathrm{C}_{4} \mathrm{H}_{6}\right] \cdot P\left[\mathrm{H}_{2}\right] / P^{2}\left[\mathrm{C}_{2} \mathrm{H}_{4}\right]$ that differ from the calculated values of the equilibrium constant by factors of the order of 100 after contact times of the order of a minute and of several seconds, respectively. In both cases these experimental values were changing with time. The well-known strong dependence of reaction rate on temperature is particularly evident in this case. The rates of many of these reactions double for each 15 to 25 degrees centigrade rise in temperature. Correlations of data for reaction rates for the thermal decomposition of several hydrocarbons will be found in a review paper by Steacie [73] and a discussion of the prediction of reaction rates is given in a paper by Daniels [74]. Numerous papers by Eyring and co-authors treat the subject of reaction rates, considering details of the structure of the activated complex, the configuration of highest energy which the reacting molecules must have in changing from reactants to products of a reaction [75].

\section{References}

[1] C. H. Meyers, R. B. Scott, F. G. Brickwedde, and R. D. Rands, Jr., Thermal properties of vapor and liquid 1,3-butadiene. Report to the Office of the Rubber Director (June 30, 1943).

[2] Russell B. Scott, Cyril H. Meyers, Robert D. Rands, Jr., Ferdinand G. Brickwedde, and Norman Bekkedahl, J. Research NBS 35, 39 (1945) RP1661.

[3] J. G. Aston, George Szasz, and F. G. Brickwedde, The heat content and free energy of butadiene 1,3 and isoprene above $25^{\circ} \mathrm{C}$. Equilibria in the dehydrogenation of $n$-butane and $n$-butenes to butadiene 1,3. Report to the Office of the Rubber Director. (July 23, 1943).
[4] John G. Aston, George Szasz, Harold W. Woolley, and Ferdinand G. Brickwedde, J. Chem. Phys. 14, 67, (1946).

[5] K. Bradacs and L. Kahovec, Z. physik. Chem. 48, 63 (1940).

[6] Kenneth S. Pitzer and Donald W. Scott, J. Am. Chem. Soc. 65, 803 (1943).

[7] J. G. Aston, G. J. Szasz, and H. L. Fink, J. Am. Chem. Soc. 65, 1135 (1943).

[8] James B. Montgomery and Thomas DeVries, J. Am. Chem. Soc. 64, 2375 (1942).

[9] K. Bennewitz and W. Rossner, Z. physik. Chem. [B] 39, 126 (1938). 
[10] Fred Stitt, J. Chem. Phys. 7, 297 (1939).

[11] J. D. Kemp and K. S. Pitzer, J. Am. Chem. Soc. 59, 276 (1937).

[12] G. B. Kistiakowsky, J. R. Lacher, and Fred Stitt, J. Chem. Phys. 7, 289 (1939).

[13] V. R. Thayer and G. Stegeman, J. Phys. Chem. 35, 1505 (1931).

[14] B. P. Dailey and W. A. Felsing, J. Am. Chem. Soc. 65, 42 (1943).

[15] A. Eucken and A. Parts, Z. physik. Chem [B] 20, 184 (1933).

[16] R. K. Witt and J. D. Kemp, J. Am. Chem. Soc. 59, 273 (1937).

[17] W. S. Galloway and E. F. Barker, J. Chem. Phys. 10, 88 (1942).

[18] M. E. Haas and G. Stegeman, J. Phys. Chem. 36, 2127 (1932).

[19] E. J. Burcik, E. H. Eyster, and D. M. Yost, J. Chem. Phys. 9, 118 (1941).

[20] C. J. Egan and J. D. Kemp, J. Am. Chem. Soc. 59, 1264 (1937).

[21] D. D. Wagman, N. E. Kilpatrick, K. S. Pitzer, and F. D. Rossini, J. Research NBS 35, 467 (1945) RP1682.

[22] Ta-You Wu, J. Chem. Phys. 8, 489 (1940).

[23] A. R. Gordon, J. Chem. Phys. 6, 219 (1938).

[24] S. C. Schumann and John G. Aston, J. Chem. Phys. 6, 480 (1938).

[25] J. G. Aston, Ind. Eng. Chem. 34, 514 (1942).

[26] Avis Borden and E. F. Barker, J. Chem. Phys. 6, 553 (1938).

[27] Hermann D. Noether, J. Chem. Phys. 10, 693 (1942).

[28] G. Bolla, Z. Physik 90, 607 (1934).

[29] Violet L. Wu and E. F. Barker, J. Chem. phys. 9, 487 (1941).

[30] John G. Aston, George J. Szasz, and Saul Isserow, J. Chem. Phys. 11, 532 (1943).

[31] Kenneth S. Pitzer, J. Chem. Phys. 8, 711 (1940).

[32] H. B. Dixon and G. Greenwood, Proc. Roy. Soc. (London) [A] 105, 199 (1924).

[33] S. K. K. Jatkar, Quart. J. Indian Inst. Sci. 2, 39 (1939).

[34] H. V. Regnault, Mem. l'Acad. Sci. Paris 26, 1 (1862).

[35] K. K. Kelley, J. Am. Chem. Soc. 51, 779 (1929).

[36] E. F. Fiock, D. C. Ginnings and W. B. Holton, BS J. Research 6, 881 (1931) RP312.

[37] A. R. Gordon, J. Chem. Phys. 2, 65 and 549 (1934).

[38] E. B. Wilson, Jr., J. Chem. Phys. 4, 526 (1936).

[39] C. C. Stephenson and H. O. McMahon, J. Chem. Phys. \%, 614 (1939).

[40] W. F. Giauque and R. C. Archibald, J. Am. Chem. Soc. 59, 561 (1937).

[41] H. F. Weber, Pogg. Ann. 154, 367 and 553 (1875); Phil. Mag. 49, 276 (1875).

[42] W. Nernst, Ann. phys. 36, 395 (1911).

[43] A. Magnus, Ann. Physik \%0, 303 (1923).

[44] P. Schlapfer and R. Debrunner, Helv. Chim. Acta 7, 31 (1924).

[45] C. J. Jacobs and G. S. Parks, J. Am. Chem. Soc. 56, 1513 (1934).

[46] A. G. Worthing, Phys. Rev. 12, 224 (1918).
[47] H. W. Woolley, F. G. Brickwedde, and R. B. Scott (publication pending).

[48] H. L. Johnston and M. K. Walker, J. Am. Chem. Soc. 55, 172 (1933), and 57, 682 (1935).

[49] J. Curry and G. Herzberg, Ann. Physik 19, 800 (1934).

[50] E. J. Prosen, R. S. Jessup, and F. D. Rossini, J. Research NBS 33, 447 (1944) RP1620.

[51] E. J. Prosen, R. Gilmont, and F. D. Rossini, J. Research NBS 34, 65 (1945) RP1629.

[52] E. J. Prosen and F. D. Rossini, J. Research NBS 34, 263 (1945) RP1642.

[53] F. D. Rossini, J. Research NBS 22, 407 (1939) RP1192.

[54] G. H. Burrows and C. Lucarini, J. Am. Chem. Soc. 49, 1157 (1927).

[55] V. R. Zharkova and A. V. Frost, J. Gen. Chem. (U. S. S. R.) 2, 534 (1932).

[56] V. Schneider and P. K. Frolich, Ind. Eng. Chem. 23, 1405 (1931).

[57] G. B. Kistiakowsky, J. Chem. Phys. 10, 78 (1942).

[58] F. E. Frey and W. F. Huppke, Ind. Eng. Chem. 25, 54 (1933); recalculated, G. B. Kistiokowsky, H. Romeyn, J. R. Ruhoff, H. A. Smith, and W. E. Vaughan, J. Am. Chem. Soc. 57, 65 (1935).

[59] A. A. Videnski and S. G. Vinikova, J. Gen. Chem. (U. S. S. R.) 4, 120 (1934)

[60] M. W. Travers and T. J. P. Pearce, J. Soc. Chem. Ind. 53, $321 \mathrm{~T}$ (1934).

[61] R. N. Pease and E. S. Durgan, J. Am. Chem. Soc. 50, 2715 (1928).

[62] M. W. Travers and L. E. Hockin, Proc. Roy. Soc. (London) [A] 136, 1 (1932).

[63] H. M. Stanley, J. E. Youell, J. B. Dymock, J. Soc. Chem. Ind. 53, $205 \mathrm{~T}$ (1934).

[64] M. P. Applebey, J. V. S. Glass, G. F. Horsley, J. Soc. Chem. Ind. 56, $279 \mathrm{~T}$ (1937).

[65] R. H. Bliss, B. F. Dodge, Ind. Eng. Chem. 29, 19 (1937).

[66] M. P. E. Berthelot, Ann. chim. phys. [4] 9, 445 (1866).

[67] E. A. Naragon, R. E. Burk, and H. P. Lankelma, Ind. Eng. Chem. 34, 355 (1942).

[68] N. Kozlov and P. Fedoseev, Synteticheskii Kauchuk, 1934 No. 5, 36-8, also, U. O. P. Co., Lib. Bul. Abs. 20, 48 (1945).

[69] J. N. Pearce and J. W. Newsome, Ind. Eng. Chem. 30, 588 (1938).

[70] F. E. Frey and H. J. Hepp, Ind. Eng. Chem. 25, 441 (1933).

[71] H. Tropsch, C. L. Thomas, G. Egloff, and J. C. Morrell, Ind. Eng. Chem. 30, 169, (1938).

[72] L. F. Marek and M. Neuhaus, Ind. Eng. Chem. 25, 516 (1933).

[73] E. W. R. Steacie, Chem. Rev. 22, 311 (1938).

[74] F. Daniels, Ind. Eng. Chem. 35, 504 (1943).

[75] H. Eyring, H. M. Hulburt, and R. A. Harman, Ind. Eng. Chem. 35, 504 (1943); S. Glasstone, K. J. Laidler, and H. Eyring, The theory of rate processes (McGraw-Hill Book Co., Inc., New York, N. Y., 1941).

WASHINGTON, March 24, 1944: 